\title{
Supplementary Motor Area and Presupplementary Motor Area: Targets of Basal Ganglia and Cerebellar Output
}

\author{
Dalila Akkal, ${ }^{2}$ Richard P. Dum, ${ }^{2}$ and Peter L. Strick ${ }^{1,2,3}$ \\ ${ }^{1}$ Pittsburgh Veterans Affairs Medical Center, ${ }^{2}$ Center for the Neural Basis of Cognition and Department of Neurobiology, and ${ }^{3}$ Department of Psychiatry and \\ Neurological Surgery, University of Pittsburgh School of Medicine, Pittsburgh, Pennsylvania 15261
}

\begin{abstract}
We used retrograde transneuronal transport of neurotropic viruses in Cebus monkeys to examine the organization of basal ganglia and cerebellar projections to two cortical areas on the medial wall of the hemisphere, the supplementary motor area (SMA) and the pre-SMA. We found that both of these cortical areas are the targets of disynaptic projections from the dentate nucleus of the cerebellum and from the internal segment of the globus pallidus (GPi). On average, the number of pallidal neurons that project to the SMA and pre-SMA is approximately three to four times greater than the number of dentate neurons that project to these cortical areas. GPi neurons that project to the pre-SMA are located in a rostral, "associative" territory of the nucleus, whereas GPi neurons that project to the SMA are located in a more caudal and ventral "sensorimotor" territory. Similarly, dentate neurons that project to the pre-SMA are located in a ventral, "nonmotor" domain of the nucleus, whereas dentate neurons that project to the SMA are located in a more dorsal, "motor" domain. The differential origin of subcortical projections to the SMA and pre-SMA suggests that these cortical areas are nodes in distinct neural systems. Although both systems are the target of outputs from the basal ganglia and the cerebellum, these two cortical areas seem to be dominated by basal ganglia input.
\end{abstract}

Key words: virus tracing; cortical motor areas; motor control; Parkinson's disease; dentate; globus pallidus

\section{Introduction}

Classically, the supplementary motor area (SMA) was defined as a single cortical field within the medial part of Brodmann's area 6 (Penfield and Welch, 1951; Woolsey et al., 1952). There have been many suggestions about the function of the SMA including involvement in the regulation of posture, bimanual coordination, the internal generation of movement, and the construction of movement sequences (Goldberg, 1985; Tanji, 1994). More recently, the region traditionally included within the SMA has been subdivided into two distinct areas: the SMA proper (SMA) and a more rostrally located presupplementary motor area (pre-SMA) (Luppino et al., 1991; Matsuzaka et al., 1992; Picard and Strick, 1996, 2001) [for additional references and review, see Tanji $(1994,1996)]$. The results of imaging studies in humans strongly support this subdivision. In general, activation in the SMA is tightly coupled to movement generation and control. However, this does not seem to be the case for the pre-SMA (Picard and Strick, 1996, 2001; Coull et al., 2004). Indeed, there are a number of instances in which activation was present in the pre-SMA dur-

Received Dec. 20, 2006; revised Aug. 9, 2007; accepted Aug. 13, 2007.

This work was supported by Veterans Affairs Medical Research and United States Public Health Service Grants MH56661 and NS24328 to P.L.S. We thank Dr. R. Dix (University of Arkansas, Little Rock, AR) for supplying HSV1 and Dr. C. Rupprecht (Centers for Disease Control, Atlanta, GA) for supplying CVS-11. We also thank Dr. A. Wandeler (Animal Diseases Research Institute, Nepean, Ontario, Canada) for supplying antibodies to rabies. We thank M. Page, B. Hartz, M. O'Malley, and C. Lovell for technical assistance and Nathalie Picard for her comments on this work. Correspondence should be addressed to Dr. Peter L. Strick, Department of Neurobiology, University of Pittsburgh School of Medicine, 4074 Biomedical Science Tower-3, 3501 Fifth Avenue, Pittsburgh, PA 15261. E-mail: strickp@pitt.edu.

DOI:10.1523/JNEUROSCI.3134-07.2007

Copyright $\odot 2007$ Society for Neuroscience $\quad$ 0270-6474/07/2710659-15\$15.00/0 ing decidedly nonmotor, cognitive tasks (Petit et al., 1998; Coull et al., 2004; Lau et al., 2004; Pouthas et al., 2005; Hon et al., 2006; Macar et al., 2006).

The SMA and pre-SMA display some important differences in their connectivity and function. For example, the SMA has dense projections to the primary motor cortex (M1) and also projects directly to the spinal cord (Muakkassa and Strick, 1979; Ghosh et al., 1987; Dum and Strick, 1991a,b, 1996, 2005; Galea and DarianSmith, 1994; He et al., 1995; Hatanaka et al., 2001; Wang et al., 2001; Maier et al., 2002). In contrast, the pre-SMA does not have substantial connections with M1 and does not project to the spinal cord (Dum and Strick, 1991a,b, 2005; Tokuno and Tanji, 1993; Galea and Darian-Smith, 1994; Lu et al., 1994; He et al., 1995; Hatanaka et al., 2001; Wang et al., 2001). Instead, the preSMA is densely interconnected with regions of prefrontal cortex (Luppino et al., 1990, 1993; Bates and Goldman-Rakic, 1993; Lu et al., 1994; Wang et al., 2005) (but see Takada et al., 2004). Surprisingly, the pre-SMA does not appear to be densely interconnected with the SMA (Luppino et al., 1990, 1993; Wang et al. 2001).

The SMA has been considered to be an important target of basal ganglia output (Schell and Strick, 1984; Wiesendanger and Wiesendanger, 1985a; Alexander et al., 1986; Darian-Smith et al., 1990; Rouiller et al., 1994, 1999; Shindo et al., 1995; Matelli and Luppino, 1996; Sakai et al., 1999, 2002). In addition, Wiesendanger and Wiesendanger (1985a,b) provided some evidence for cerebellar input to the SMA, especially to its rostral portion, which is now recognized as the pre-SMA. However, despite several elegant studies (Rouiller et al., 1994; Sakai et al., 1999, 2000, 2002), the organization of basal ganglia and cerebellar input to the pre-SMA 
and SMA remains uncertain because of the complexities of thalamic nomenclature and the disynaptic nature of cerebellothalamocortical and basal ganglia-thalamocortical connections.

Here we used retrograde transneuronal transport of neurotropic viruses to define the organization of basal ganglia and cerebellar projections to the SMA and pre-SMA. There are three main observations of the present study. First, we found that the SMA and the pre-SMA are the targets of outputs from both the basal ganglia and the cerebellum. Second, our results indicate that the SMA and pre-SMA each receives relatively more basal ganglia input than cerebellar input. Thus, the two cortical areas seem to be dominated by basal ganglia input. Third, projections to the SMA and pre-SMA originate from spatially separate and neurochemically distinct regions within globus pallidus (GPi) and dentate. The differential origin of subcortical projections to the SMA and pre-SMA suggests that these cortical areas are nodes in distinct neural systems. Some of these results have been reported in preliminary form (Akkal et al., 2001, 2002b, 2003).

\section{Materials and Methods}

This study is based on observations from eight juvenile Cebus monkeys (Cebus apella; 1.3-2.4 kg; four males and four females) (Table 1). We placed multiple injections of virus into the SMA $(n=7)$ or into the pre-SMA $(n=3)$. In most cases, the virus injection into the SMA was centered on the hand representation (e.g., fingers and wrist), but in one case, the entire arm representation of the SMA was injected. In two cases, virus was injected into the SMA of one hemisphere and into the pre-SMA of the opposite hemisphere.

All experimental procedures were in accordance with the regulations detailed in the National Institutes of Health Guide for the Care and Use of Laboratory Animals. All protocols were approved by the Institutional Animal Care and Biosafety Committees. Biosafety practices conformed to the Biosafety Level 2 regulations outlined in Biosafety in Microbiological and Biomedical Laboratories (Department of Health and Human Services publication number 93-8395). Details of the procedures for handling virus and virus-infected animals were published previously (Strick and Card, 1992; Hoover and Strick, 1999; Kelly and Strick, 2000, 2003).

Surgical procedures. Twelve hours before surgery, food and water were removed and dexamethasone $(0.5 \mathrm{mg} / \mathrm{kg}, \mathrm{i} . \mathrm{m}$. $)$ was given. Before surgery, animals were pretreated with glycopyrrolate $(0.01 \mathrm{mg} / \mathrm{kg}$, i.m. $)$. Animals were sedated with ketamine (15-20 mg/kg, i.m.), intubated, and anesthetized and maintained with isoflurane $(1.5-2.5 \% ; 1-3 \mathrm{~L} / \mathrm{m})$ in a $2: 1 \mathrm{mix}-$ ture of oxygen and air. Dexamethasone $(0.5 \mathrm{mg} / \mathrm{kg}$, i.m. $)$ and an antibiotic $(75 \mathrm{mg} / \mathrm{kg}$ ceftriaxone, i.m.) were administered at this time. Respiratory rate, heart rate, blood oxygen saturation, and sensitivity to noxious stimuli were monitored during the surgery. Hydration was maintained using lactated Ringer's solution $(5 \mathrm{ml} / \mathrm{kg} / \mathrm{h}$, i.v. $)$. Body temperature was maintained using a heating pad. Just before physiological mapping (see below), the animals were removed from isoflurane and anesthetized with Telazol (initial dose, $4 \mathrm{mg} / \mathrm{kg}$, i.m.; supplemental dose, 2-4 mg/kg/h, i.m.). The analgesic butorphanol $(0.1 \mathrm{mg} / \mathrm{kg}$, i.m.) was given every $2-4 \mathrm{~h}$. In some cases, the animals were returned to isoflurane anesthesia before the injections of virus that followed cortical mapping.

All surgical procedures were performed using aseptic techniques. The animal's head was placed in a stereotaxic frame (David Kopf Instruments, Tujunga, CA), and ophthalmic ointment was used to protect its eyes. A local anesthetic (buvipicaine) was injected subcutaneously along the incision lines. The skin was incised and retracted to expose the skull over one or both hemispheres. A bolt was then attached to the posterior part of the skull with small screws and dental acrylic. The bolt was used to stabilize the head during physiological mapping (see below). A large craniotomy was performed over the region of interest. Then, the dura was opened and reflected medially to expose the crest of the medial part of the superior frontal gyrus. The exposed cortex was covered with warm surgical-grade silicone (1500 cSt; Dow Corning, Midland, MI).

Electrophysiological mapping. Our overall goal for mapping was to define functional borders between the cortical areas of interest. Prolonged mapping in anesthetized animals is not consistent with survival times important for studies using viruses as tracers. For SMA injections, we focused on defining the location of the forelimb digits because this representation is centrally located within the SMA and far from its rostral and caudal borders. For pre-SMA injections, we searched for the rostral border of the SMA where face movements can be evoked. Then, we moved just rostral to this region to sites where intracortical stimulation seldom evoked movement or evoked movement only when high current strengths were used.

The cortical region of interest was photographed using a video camera/ computer system. The pictures included important surface landmarks such as cortical sulci as well as the pattern of surface blood vessels. We mapped the SMA using intracortical stimulation (33 cathodal pulses, 0.2 ms duration, $333 \mathrm{~Hz}$ frequency, 1-60 uA intensity) with parylene-coated Elgiloy microelectrodes (Bak Electronics, Mount Airy, MD) (impedance 0.6-1.2 M $\Omega$ at $1 \mathrm{kHz}$ ) (Suzuki and Azuma, 1976). Higher current intensities were used for mapping the pre-SMA (up to $80 \mu \mathrm{A}$ ). The stimulus intensity was monitored by an isolated current probe that measured the current passing through the wire to the microelectrode. Microelectrode penetrations, spaced $0.5-1 \mathrm{~mm}$ apart, were made into the SMA and pre-SMA. Stimulation was delivered every $500 \mu \mathrm{m}$, beginning $2.0 \mathrm{~mm}$ below the cortical surface and extending an additional $4-5 \mathrm{~mm}$. We limited the number of penetrations to reduce the length of time the animal was under anesthesia and to minimize potential damage to the cortex by the stimulating electrode. The movement evoked at each stimulation site was determined by visual inspection and muscle palpation. The threshold current for each response was defined as the stimulus intensity that evoked movement in $\sim 50 \%$ of the trials. The location of the penetration, the depth of stimulation site, and the evoked movement and its threshold were entered into a computer program that generated a map of the stimulation sites. These maps were used to guide tracer injections into the SMA and pre-SMA.

Virus injections. In our first two animals (DA1L and DA2L), we injected the hand representation of the SMA with the McIntyre-B strain of herpes simplex virus type 1 (HSV1; $1.0 \times 10^{11}$ plaque-forming units $(\mathrm{pfu}) / \mathrm{ml}$; supplied by Dr. R. Dix, University of Arkansas, Little Rock, AR). In all subsequent animals $(n=6)$, we injected the SMA or the pre-SMA with CVS-11 (challenge virus strain 11 of rabies virus; $1.0 \times$ $10^{7} \mathrm{pfu} / \mathrm{ml}$; supplied by Dr. C. Rupprecht, Centers for Disease Control, Atlanta, GA) (Table 1). In general, the injections into the SMA were placed every $0.5 \mathrm{~mm}$ at depths $2-5 \mathrm{~mm}$ below the cortical surface. Injections into the pre-SMA were placed every $0.5 \mathrm{~mm}$ at depths $1-4.5 \mathrm{~mm}$ below the cortical surface. The injections of virus were made with a 28 gauge needle attached to a $5 \mu \mathrm{l}$ Hamilton (Reno, NV) syringe. In most cases, the injection needle penetrated parallel to the medial wall. In one animal (DA6), the opposite hemisphere was gently retracted to allow a needle with a $90^{\circ}$ bend to penetrate perpendicular to the medial wall. The volume of virus injected at each location was 0.2 or $0.3 \mu \mathrm{l}$. After each injection, the syringe was left in place for $2 \mathrm{~min}$. When all injections were completed, the surface of the brain was washed with warm sterile saline. Then, the dura and the bone flap were repositioned, and the incision was closed.

Survival period. After the surgery, animals that received injections of HSV1 or rabies were placed in a BSL-2 isolation room for observation and recovery. The behavior and appearance of each animal were recorded every $4-8 \mathrm{~h}$, or more often if needed. All animals received dexamethasone $(0.25-0.5 \mathrm{mg} / \mathrm{kg}$, i.m. or p.o.) during the first $3 \mathrm{~d}$ of the survival period. Animals were administered buprenorphine $(0.01 \mathrm{mg} / \mathrm{kg}$, i.m.; every $12 \mathrm{~h}$ ) postoperatively. If an animal developed focal or generalized seizures after an injection of HSV1, it was treated with phenobarbital $(8-10 \mathrm{mg} / \mathrm{kg}$, i.m.).

The survival time was chosen to allow retrograde transport of virus from the cortical injection site to first-order neurons in the thalamus and then retrograde transneuronal transport of virus from the infected thalamic neurons to second-order neurons in the basal ganglia and cerebellum (Hoover and Strick, 1999; Kelly and Strick, 2003). The optimal survival time for second-order labeling with rabies virus is somewhat shorter than that for HSV1 (Table 1). At the end of the survival period, each animal was deeply anesthetized $(25 \mathrm{mg} / \mathrm{kg}$ ketamine, i.m., followed 

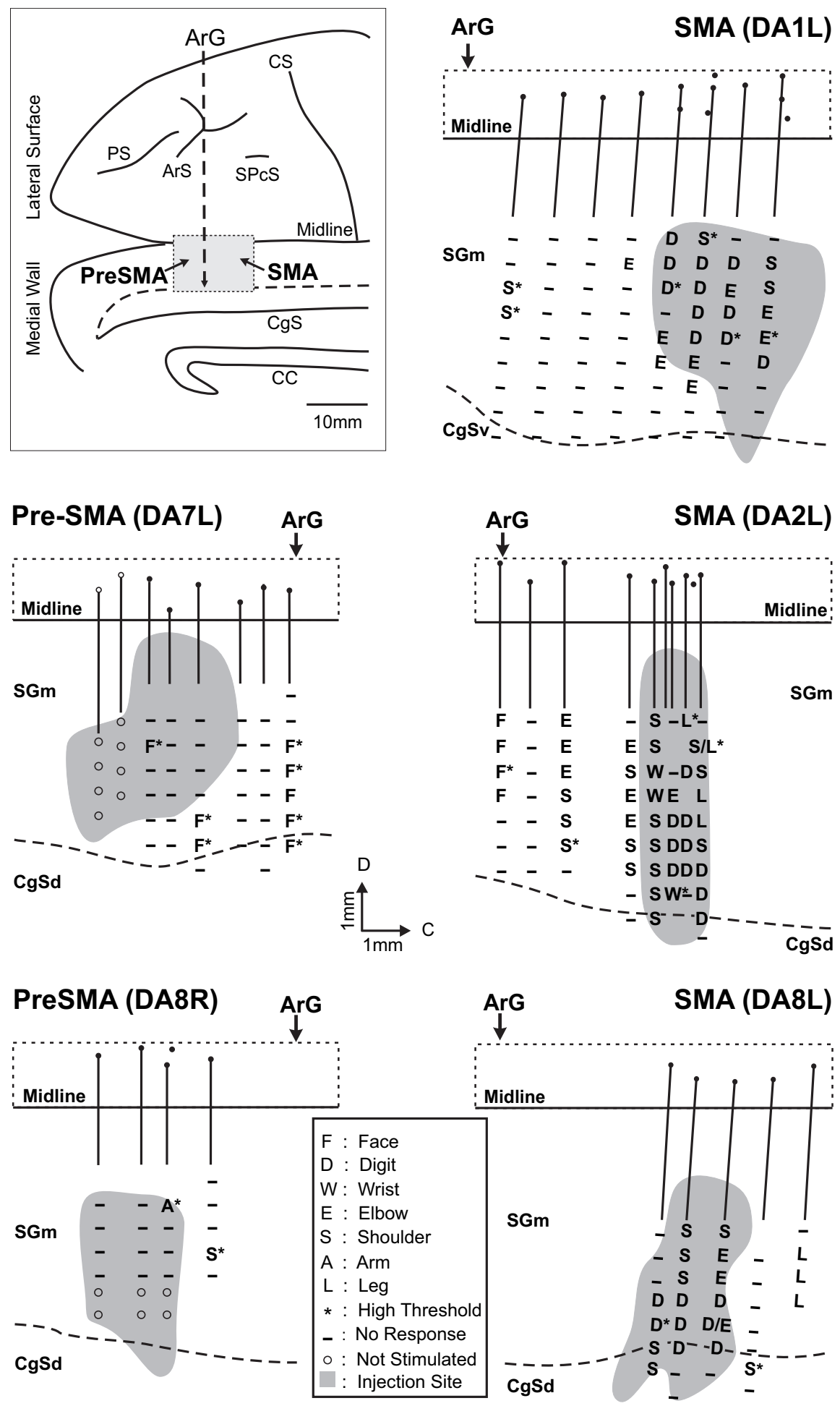

Figure 1. Location of injection sites in the SMA and pre-SMA. In the top left inset, the regions containing the SMA and pre-SMA are outlined on dorsal and medial views of the right hemisphere of a Cebus monkey. The right panels show maps of the intracortical stimulation and injection sites in the SMA of three monkeys (DA1, DA2L, and DA8L). The bottom left panels show maps of the intracortical stimulation and injection sites in the pre-SMA of two monkeys (DA7L and DA8R). The site of each microelectrode penetration (vertical line) in each map is indicated on the cortical surface by a dot. Tracks where no stimulation was attempted are indicated by open dots. The motor response evoked by stimulation along each track is indicated by a letter code at each stimulation site (see legend between the bottom right and left panels). The shaded region in each panel indicates the virus injection site. The asterisks indicate sites were the threshold to evoke movement was $>50 \mu \mathrm{A}$. ArS, Arcuate sulcus; ArG, level of the genu of the arcuate sulcus; $C \mathrm{CS}$, central sulcus; $\mathrm{PS}$, principal sulcus; $\mathrm{SPCS}$, superior precentral sulcus; $\mathrm{CC}$, corpus callosum; $\mathrm{CgS}$, cingulate sulcus; SGm, medial part of the superior frontal gyrus; $C g S d$, dorsal bank of the cingulate sulcus; CgSv, ventral bank of the cingulate sulcus. by $37 \mathrm{mg} / \mathrm{kg}$ sodium pentobarbital, i.p.) and perfused transcardially with a three-step procedure (Rosene and Mesulam, 1978). The perfusates included (1) $0.1 \mathrm{M}$ phosphate buffer, (2) $10 \%$ buffered formalin, and (3) 10\% buffered formalin with $10 \%$ glycerol added. After the perfusion, the brain was removed, photographed, and stored in $10 \%$ buffered formalin with $20 \%$ glycerol $\left(4^{\circ} \mathrm{C}\right)$ for $5-7 \mathrm{~d}$.

Histological procedures. Frozen blocks of tissue were sectioned $(50 \mu \mathrm{m})$ in the coronal plane, and each section was placed serially into one of 100 wells. Every 10th section was stained with cresyl violet for the analysis of cytoarchitecture. To identify virus-infected neurons, we processed every other section as free-floating tissue according to the avidin-biotin peroxidase method (Vectastain; Vector Laboratories, Burlingame, CA). Rabies antigen was detected using a monoclonal antibody directed against the rabies virus nucleoprotein (5DF12, diluted $1: 100)$ or the rabies virus phosphoprotein (M957, diluted 1:300) (both supplied by Dr. A. Wandeler, Animal Diseases Research Institute, Ottawa, Ontario, Canada). Comparable numbers of infected neurons were labeled by the two antibodies. HSV1 was detected using a commercially available polyclonal antibody (diluted 1:2000; Dako, Carpinteria, CA). Reacted sections were mounted on gelatin-coated glass slides, air dried, and coverslipped with either Artmount or DPX (a mixture of distyrene, tricresyl phosphate, and xylene).

We examined the staining pattern for the monoclonal antibody $8 \mathrm{~B} 3$ on sections through the dentate nucleus $(n=2)$. This antibody recognizes a chondroitin sulfate proteoglycan that is expressed on the cell surface of subpopulations of neurons (Pimenta et al., 2001). More importantly, antibody $8 \mathrm{~B} 3$ is a marker of the "nonmotor domain" of the dentate in the monkey (Dum et al., 2002). Sections through the dentate were incubated for $18-22 \mathrm{~h}$ in monoclonal antibody $8 \mathrm{~B} 3$ diluted 1:8000 in Blotto (4\% nonfat dry milk in $0.1 \mathrm{M}$ PBS, pH 7.4) and $2 \%$ Triton X-100. After several washes in PBS, the sections were incubated for $2 \mathrm{~h}$ in the secondary antibody (goat anti-mouse IgM-HRP conjugate, $\mu$-chain specific; Jackson ImmunoResearch, West Grove, PA), diluted 1:100 with Blotto, $2 \%$ Triton X-100, and 0.01\% thimerosal. The antigen-antibody complexes were revealed by reaction in $3,3^{\prime}-$ diaminobenzidine $0.05 \%$ in PBS and $0.01 \%$ $\mathrm{H}_{2} \mathrm{O}_{2}$.

We also examined the staining pattern for a monoclonal antibody that recognizes a calcium-binding protein, calbindin D-28K, on sections through GPi $(n=2)$. Calbindin is a marker of the "associative territory" of the striatum in the monkey (François et al., 1994). Sections through GPi were incubated for $24 \mathrm{~h}$ in the calbindin D-28K mouse monoclonal IgG antibody (CH-6501; Swant, Bellinzona, Switzerland) diluted 1:8000 in $0.1 \mathrm{M}$ phosphate Tris (PT) buffer with sodium azide, $\mathrm{pH} 7.5$, and $0.5 \%$ Triton X-100. After several washes in PT, the sections were incubated for $1 \mathrm{~h}$ in the secondary antibody (horse anti-mouse biotinyl- 
ated IgG; Vector Laboratories) with $0.5 \%$ Triton X-100 in PT. Finally, the sections were washed and incubated for $1 \mathrm{~h}$ to reveal the location of antigen according to the avidin-biotin peroxidase method (Vectastain; Vector Laboratories).

Analytic procedures. Every other section through the dentate nucleus of the cerebellum and the internal segment of the GPi was examined for labeled neurons under bright-field illumination. Section outlines, labeled neurons, and injection sites were plotted using a computer-based charting system (MD2; Accustage, St. Paul, MN) (for details, see Hoover and Strick, 1999; Middleton and Strick, 2001a). Digital images of selected structures were obtained using a video camera coupled to a highresolution video-processing board in a personal computer. Software written in the laboratory enabled us to generate high-resolution composites from multiple images.

Determination of injection sites. Three concentric zones of labeling characterized HSV1 virus injection sites (for details, see Hoover and Strick, 1999). Zone I contained the needle track and the highest density of viral staining and pathology. In some instances, the tissue in this zone disintegrated during tissue processing. Zone II contained a dense accumulation of infected neurons and glia, as well as a high degree of background staining. Zone III contained large numbers of labeled neurons but little or no background staining. The injection site was defined as zone I and zone II. To reconstruct the HSV1 injection sites, we first plotted the outline of the medial wall from sections through the injection site and added all three zones of labeling. We then created a flattened map of the medial wall at the level of the injection site [for the technique of unfolding the medial wall, see Dum and Strick (1991a)].

Staining for rabies virus at injection sites was less dense than the staining for HSV1 at comparable injection sites. Sites where rabies was injected were well preserved and did not contain intense background staining, glial labeling, or pathology (Gillet et al., 1986; Kelly and Strick, 2003). To assess the extent of each rabies injection site, we plotted the location of needle tracks and labeled neurons on the medial wall. We created flattened maps of the medial wall and did a density analysis (for details, see Dum and Strick, 1991a). We defined the rabies injection site as the region surrounding the injection needle tracks that contained the highest density of labeled cells (Kelly and Strick, 2003).

Maps of virus labeling in dentate and GPi. To examine the distribution and density of labeled neurons in the dentate and in GPi, we generated unfolded maps of each nucleus using software written in the laboratory. The procedure for unfolding the dentate has been described in detail previously (Dum and Strick, 2003). Briefly, we drew a curved line through the middle of the dentate on each charted section of the nucleus. We marked transition points between the major segments of the dentate. Then, these marks and labeled neurons were projected onto the central line. The central line from each section was unfolded and aligned on the transition between the major vertical and ventral segments of the dentate. To examine the density of labeled neurons, we divided the unfolded lines into $200 \mu \mathrm{m}$ intervals and totaled the number of labeled neurons in each interval. The values of the intervals from adjacent sections were combined to form $200 \times 200 \mu \mathrm{m}$ bins. The number of labeled cells in each bin was converted to a color code for display (see Figs. 3, 5).

We also created separate unfolded maps of the inner and the outer portions of GPi (see Figs. 9-11). In this case, we drew a curved line midway through the inner portion of GPi and another curved line through the outer portion of GPi. Then, labeled neurons were projected onto each of the lines. The lines were unfolded and aligned on the ventral edge of the GPi. We examined the density of labeled neurons on the maps of the two portions of GPi using the same procedures described above for the maps of the dentate.

Maps of antibody staining in dentate and GPi. We created an unfolded map of 8 B3 staining intensity in the dentate nucleus and maps of calbindin staining in the two portions of GPi. In each case, the immunostained sections were photographed using a high-resolution video camera connected to a computer. We used commercial software to adjust the overall intensity of each captured image to compensate for global differences in staining intensity between sections. We removed intensities corresponding to unstained white matter (background) using digital thresholding. A thick line was drawn down the center of the dentate (30 pixels in width or $150 \mu \mathrm{m}$ wide). Similar thick lines were drawn through the inner and outer portions of the GPi (99 pixels in width or $890 \mu \mathrm{m}$ wide). The thickness of each line was reduced to a single pixel by assigning the average value along the width to the central pixel. Then, the lines through the dentate and GPi were unfolded and aligned as described above. We smoothed the values of the intensities along each line using a sliding box filter (7 pixels in width) and interpolated between sections to construct a continuous map. We divided the staining intensity into multiple levels based on increments of SD from the mean intensity.

\section{Results}

The arm representation in the SMA of the Cebus monkey, like that of the macaque, is located caudal to the genu of the arcuate sulcus (Fig. 1, right column). Stimulation rostral to the arm representation evoked face movements (Fig. 1, DA2L), and stimulation caudal to the arm evoked leg movements (Fig. 1, DA2L and DA8L). Thus, the body map in the SMA of the Cebus monkey appears comparable to that observed in the macaque (Brinkman and Porter, 1979; Macpherson et al., 1982; Mitz and Wise, 1987; Alexander and Crutcher, 1990; Luppino et al., 1991). Within the arm representation of the SMA, hand movements (fingers and 
SMA (DA8L)

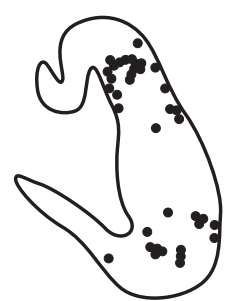

184-192

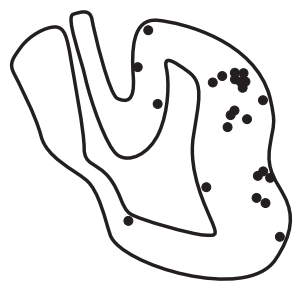

210-218

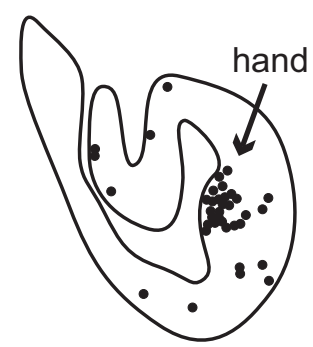

220-228

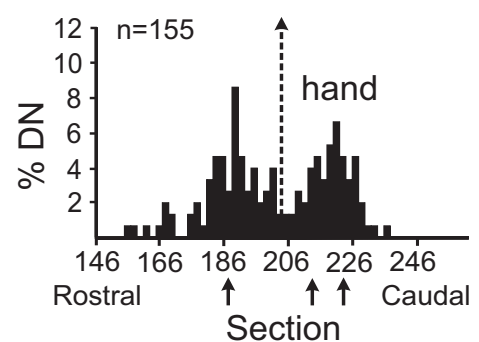

SMA (DA2L)

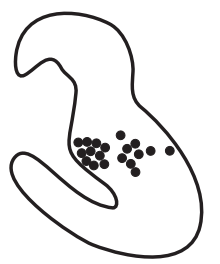

134-142
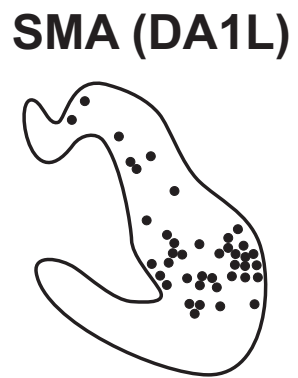

$132-140$

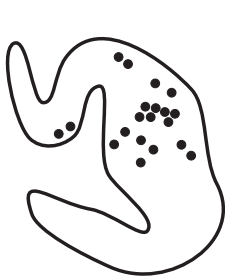

160-168

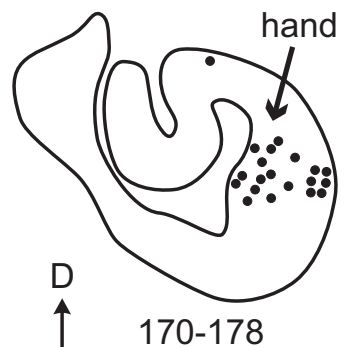

$170-178$

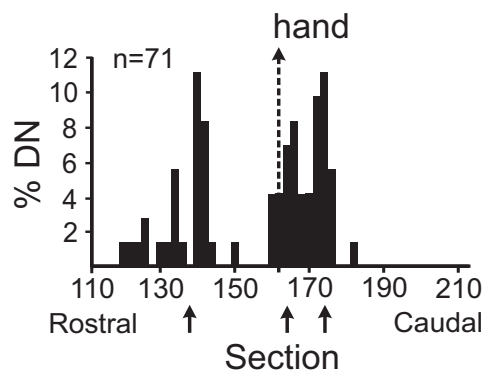

$\mathrm{M} \underset{2 \mathrm{~mm}}{\longleftarrow}$

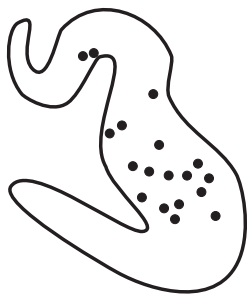

148-156

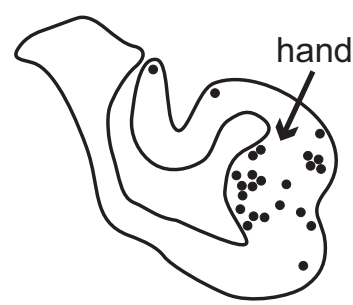

$160-168$

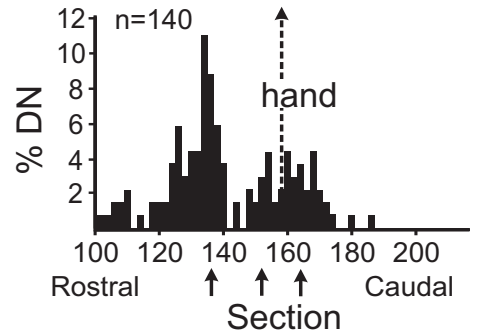

Figure 2. Second-order labeling in the dentate nucleus after virus injections into the SMA. Left, Coronal sections through the dentate nucleus of animals that received injections of virus into the SMA. Each black dot indicates the location of an infected neuron labeled by retrograde transneuronal transport (second-order neurons). Labeled cells from five sections spaced $100 \mu \mathrm{m}$ apart are superimposed on each outline of the dentate. Section numbers are indicated below each plot. M, Medial; D, dorsal. Note that one cluster of labeled neurons (indicated by arrow "hand") was present in all cases in which the injection site in the SMA included its hand representation. Right, Histograms of the rostrocaudal distribution of labeled neurons in the dentate for each case. Arrows indicate the levels of the sections plotted on the left. Dashed arrows indicate the rostrocaudal midpoint of each nucleus. $n$, The number of neurons labeled in each case (from counts of every other section); $\%$ DN, percentage of total labeled cells in the dentate nucleus.

wrist) were evoked from a central region that was surrounded by sites where movements of the elbow and shoulder were elicited (Fig. 1, DA1L). The hand representation in the SMA was typically located 3-5 mm caudal to the genu of the arcuate sulcus and at depths 2-5 mm below the cortical surface. The rostral part of the digit representation was close to the surface, whereas the caudal part was deeper on the medial wall, near the dorsal bank of the cingulate sulcus. The mean threshold for evoking movement after stimulation of the SMA was $\sim 30 \mu \mathrm{A}$.

Intracortical stimulation at sites rostral to the SMA in the pre-SMA rarely evoked movements (Fig. 1, left column). The movements that were evoked from the pre-SMA were weak, slow, and required high current intensity $(70-80 \mu \mathrm{A})$. Thus, the location of the pre-SMA in the Cebus monkey and its physiological characteristics are comparable to those of the pre-SMA in the macaque (Luppino et al., 1991; Matsuzaka et al., 1992; Inase et al., 1996).

\section{Injection sites}

SMA

In 7 animals, we injected virus into sites within the SMA where stimulation evoked hand movements (Table 1; Fig. 1, right col- umn). Histological reconstructions indicated that in all animals, the injection site included not only portions of the hand representation but also varying amounts of the adjacent elbow and/or shoulder representation. In two animals (DA2L and DA5L), the injection site also included a small portion of the adjacent leg representation. In no case did virus spread to the white matter or to the nearby cingulate motor areas.

\section{Pre-SMA}

We injected virus into the pre-SMA of three animals (Table 1; Fig. 1, left column). Before these injections, we mapped each animal using intracortical stimulation to define the pre-SMA. In animals DA7L and DA9R, we specifically searched for the rostral portion of the SMA where the face is represented. We then placed virus injections in regions of the pre-SMA that were at least $1 \mathrm{~mm}$ anterior to the most rostral site in the SMA where intracortical stimulation evoked face movements. In the other animal (DA8R), we located the face representation in the contralateral hemisphere as part of the process of defining injection sites into the SMA. The injections into the pre-SMA were placed at least 1 $\mathrm{mm}$ anterior to the most rostral site in the contralateral SMA where intracortical stimulation evoked face movements. In both 
of these cases, the virus injections were located $>2 \mathrm{~mm}$ anterior to the most rostral site in the ipsilateral SMA where arm movements could be evoked at low threshold $(<40 \mu \mathrm{A})$. Histological reconstructions indicated that all of the injection sites in the pre-SMA were placed between the level of the genu of the arcuate sulcus and the rostral extent of its superior limb. Virus was confined to the agranular cortex of the pre-SMA [F6 (Luppino et al., 1991)] and did not spread rostrally to prefrontal area $8 \mathrm{~b}$ or area $9 \mathrm{~m}$ where an incipient granular layer IV becomes evident (Petrides and Pandya, 1999) (see also Walker, 1940; Middleton and Strick, 2001a). In addition, virus did not spread ventrally to the rostral cingulate motor area (Dum and Strick, 2005), laterally to the supplementary eye field (Schlag and Schlag-Rey, 1987) or caudally to the SMA (Luppino et al., 1991).

\section{Retrograde transneuronal transport to} the cerebellum and basal ganglia

After virus injections into the SMA or the pre-SMA, we found substantial numbers of second-order neurons labeled in two major subcortical sites: dentate nucleus of the cerebellum and GPi in the basal ganglia. In the cerebellum, a few neurons were occasionally labeled in interpositus (mean of 2.7 neurons per animal) and fastigial (mean of 0.8 neurons per animal) nuclei after injections into the SMA, but not after pre-SMA injections. In all cases, the labeled neurons in the cerebellar nuclei were located contralateral to the injection site. No infected neurons were found in the cerebellar cortex, which confirms that our survival times allowed transneuronal transport of virus only to second-order neurons in cerebello-thalamocortical circuits (Kelly and Strick, 2003).

In GPi, the neurons labeled after SMA or pre-SMA injections were located ipsilateral to the injection site. Few, if any, labeled neurons were found in the substantia nigra pars reticulata (SNpr) after injections into the SMA or pre-SMA. The SNpr has substantial disynaptic projections to area $9 \mathrm{~m}$ in Cebus monkeys (Middleton and Strick, 2002). Thus, the absence of labeling in SNpr provides additional evidence that our injection sites in the pre-SMA did not spread to include area $9 \mathrm{~m}$. No infected neurons were found in the external segment of the GPi, the striatum, or the subthalamic nucleus. These results confirm that our survival times allowed transneuronal transport of virus only to secondorder neurons in the basal ganglia-thalamocortical circuits (Kelly and Strick, 2004).

The number of neurons labeled in GPi and dentate after injections into the SMA or pre-SMA differed from animal to animal (Table 2$)$. The variation after SMA injections $(\sim 4.5$ times $)$ was greater than that after pre-SMA injections $(\sim 1.7$ times). Similar variations in the number of neurons labeled in the thalamus have been observed after small injections of conventional tracers into the SMA ( $\sim 4.0$ times) or the pre-SMA ( $\sim 2.0$ times) (Matelli and Luppino, 1996). Consequently, it is likely that the differences in the number of labeled neurons among animals is primarily attributable to variations in the location of injection sites, especially for virus injections into the SMA. Despite these differences, the average total numbers of neurons labeled in GPi and dentate after
SMA and pre-SMA injections were similar (SMA, 306 vs preSMA, 248).

\section{Origin of dentate projections to the SMA and pre-SMA $S M A$}

On average, we found 97 infected neurons in the dentate of animals that received virus injections into the SMA (Table 2). However, the number of labeled neurons in the dentate of individual animals ranged from as few as 17 to as many as 155 . These counts are based on examining every other section through the nucleus of each animal.

Almost all of the labeled neurons were located in the dorsal portion of the dentate (Figs. 2, 3). The precise location of clusters of labeled neurons within the dorsal dentate displayed some variation among animals. However, one cluster of labeled neurons was consistently present in all animals (Figs. 2, 3, hand). This cluster was located in dorsal dentate just caudal to the middle of the nucleus. We believe that this cluster projects to the hand representation of the SMA, because all of our virus injections included at least a portion of this cortical region.

\section{Pre-SMA}

On average, we found 53 infected neurons in the dentate of animals that received virus injections into the pre-SMA (Table 2). Almost all of the labeled neurons were located in the ventral portion of the dentate (Figs. 4, 5). Within this region, a dense patch of labeled neurons was consistently located in the caudal one-third of the nucleus. Overall, the dentate neurons that project to the pre-SMA were clearly ventral and caudal to the dentate neurons that project to the SMA.

\section{Relationship of cerebellar outputs to $8 \mathrm{~B} 3$ immunoreactivity} In previous studies, we found that antibody $8 \mathrm{~B} 3$ differentially stains the "motor" and nonmotor domains of the dentate (Pimenta et al., 2001; Dum et al., 2002, Dum and Strick, 2003). To 


\section{Pre-SMA (DA8R)}

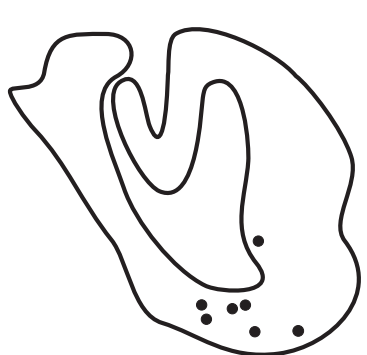

214-222

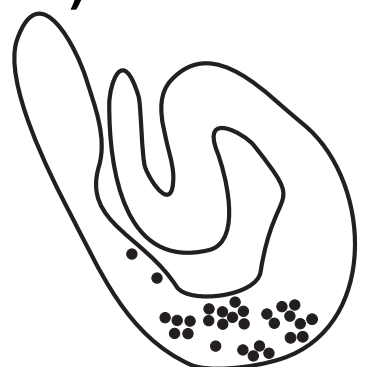

224-232

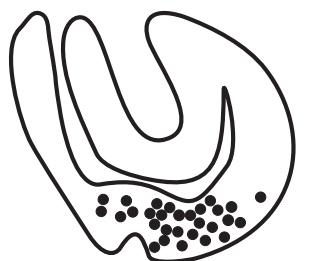

234-242

\section{Pre-SMA (DA7L)}

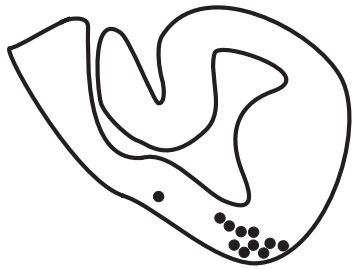

190-198

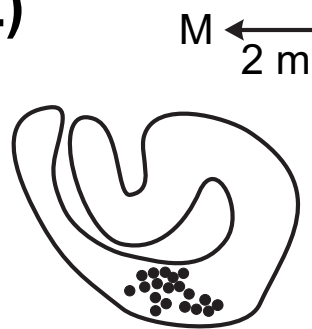

200-208

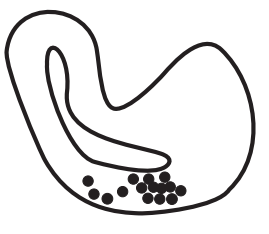

210-218
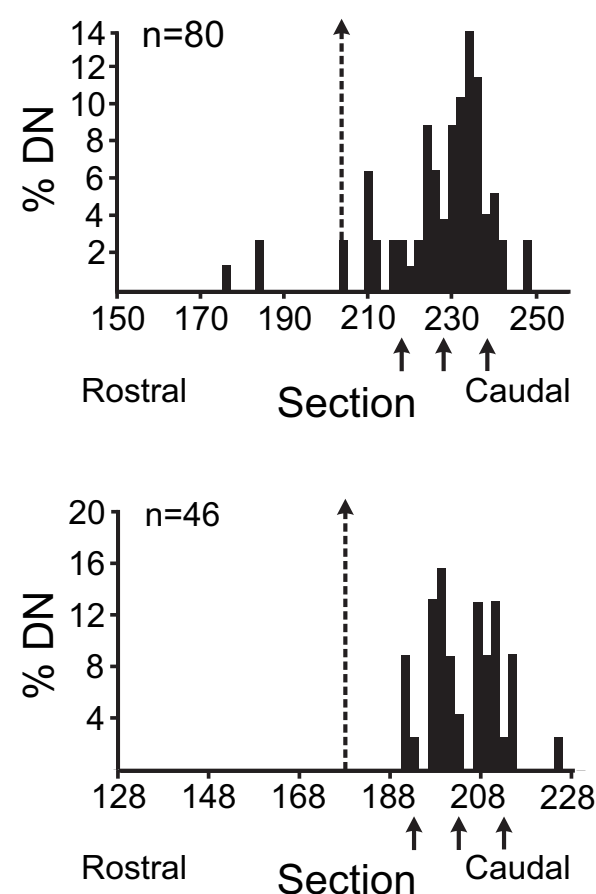

Figure 4. Second-order labeling in the dentate nucleus after virus injections into the pre-SMA. Conventions are as in Figure 2.
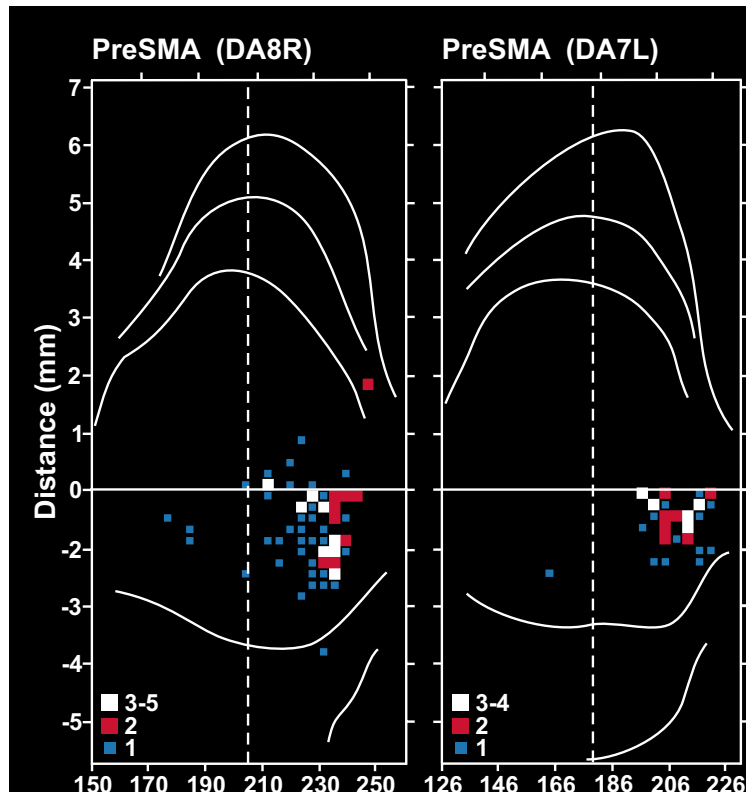

Section Number

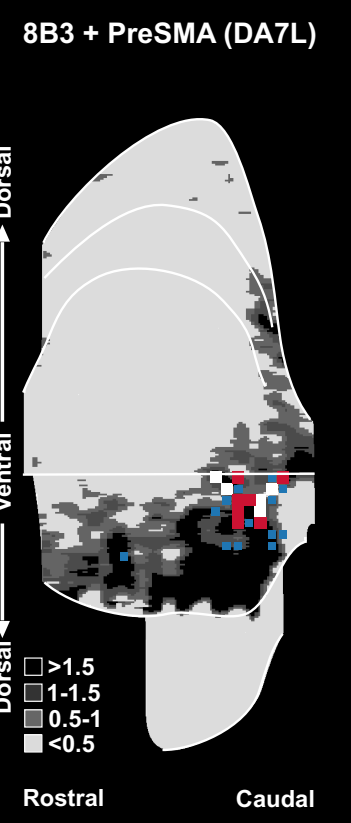

Figure 5. Unfolded maps of the dentate neurons that project to the pre-SMA. Conventions are as in Figure 3. On the right, a gradient density map of staining in the dentate of DA7L with antibody 8B3 [adapted from Dum et al. (2002)] is shown. The intensity of $8 \mathrm{~B} 3$ immunoreactivity was contoured into four grayscale levels from the most intense staining (darkest) to the least intense staining (lightest). The units are in SDs from the mean. The location of dentate neurons labeled after a virus injection into the pre-SMA of this animal is overlaid on this map.

determine how the origins of dentate projections to the SMA and pre-SMA relate to the two domains, we compared the distribution of labeled neurons after cortical injections with the pattern of $8 \mathrm{~B} 3$ staining in the same animals. In general, we found that the neurons labeled after virus injections into the
pre-SMA were located in the ventral region of the dentate that stained densely for $8 \mathrm{~B} 3$ (i.e., the nonmotor domain of the nucleus) (Figs. 5, 6). In contrast, neurons labeled after virus injections into the SMA were located in the dorsal region of the dentate that stained weakly for $8 \mathrm{~B} 3$ (i.e., the motor domain of the nucleus) (Figs. 3, 5, 6). Thus, the two cortical areas receive input from topographically separate and antigenically different domains in the dentate.

Origin of pallidal projections to the SMA and pre-SMA

SMA

Virus injections into the SMA labeled neurons in both the inner and outer portions of GPi. The number of labeled neurons in GPi of individual animals ranged from as few as 45 to as many as 451 but averaged 209 (Table 2). These counts are based on examining every other section through the nucleus of each animal.

We were unable to identify a clear focus for the origin of GPi projections to the hand area of the SMA. However, the neurons labeled after SMA injections of virus were consistently located in a broad central region of the inner and outer portions of GPi (Fig. 7). In several animals, labeled neurons formed a ringlike arrangement of labeled neurons that spanned the two portions of the nucleus (Fig. 7, animal DA8L, sections 432-440; animal DA4L, sections 398-406 and 418-426). This arrange- 


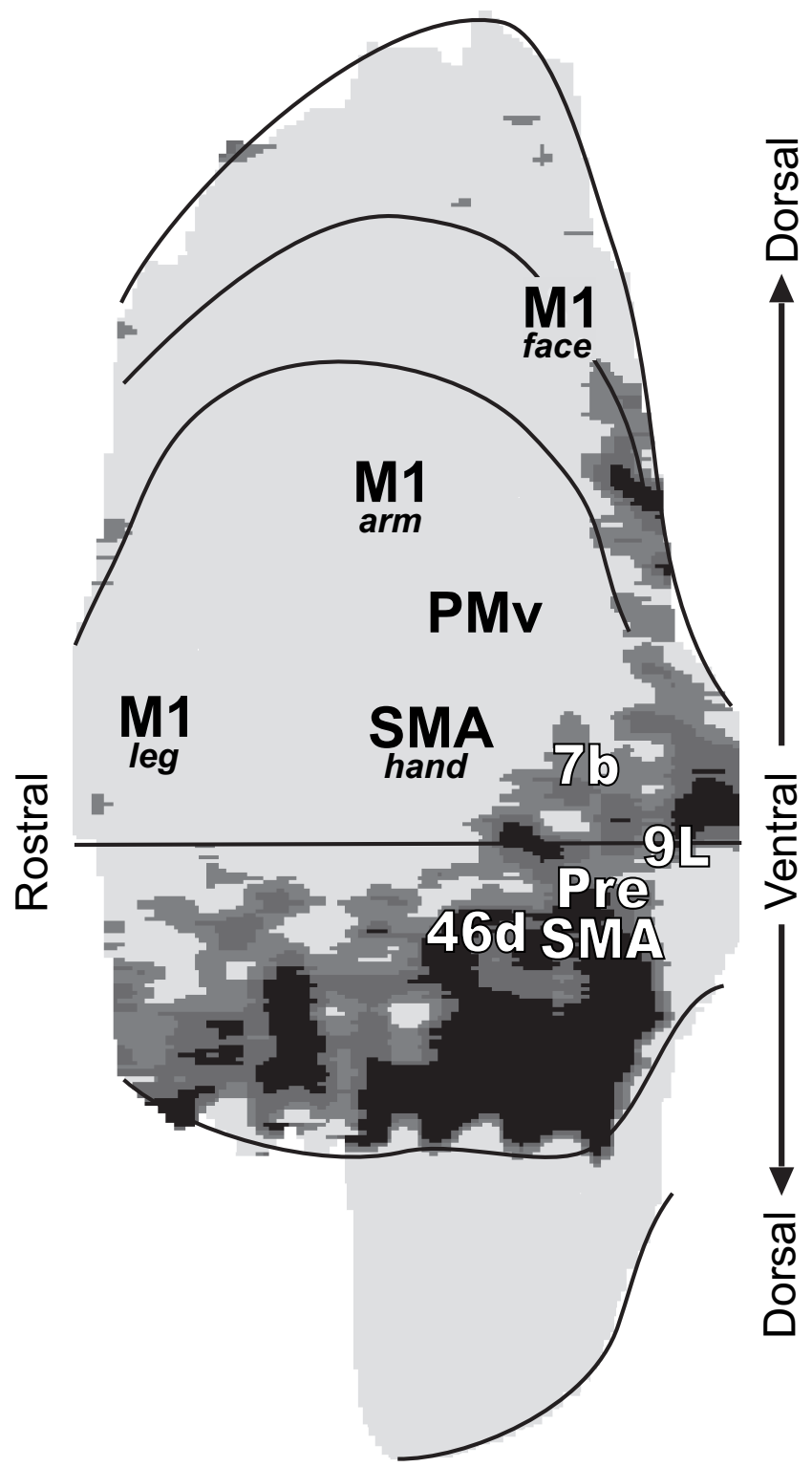

Figure 6. Summary map of the dentate output channels and their relationship to $8 \mathrm{~B} 3 \mathrm{im}$ munoreactivity. The location of known output channels in the dentate is overlaid on a map of $8 \mathrm{~B} 3$ staining. The cortical target of the output channel is placed at the site of the peak labeling after retrograde transneuronal transport of virus from that cortical area [adapted from Dum and Strick (2003)].

ment of labeled neurons is quite unlike the more homogeneous distribution of labeled neurons in GPi seen after virus injections into M1 or into areas of prefrontal cortex (Hoover and Strick, 1999; Middleton and Strick, 2002). The significance of this circular arrangement is unclear, but it may reflect some integrative aspect of SMA interconnections within the basal ganglia (Takada et al., 1998a,b; Kaneda et al., 2002).

\section{Pre-SMA}

Virus injections into the pre-SMA labeled an average of 195 neurons in the inner and outer portions of GPi (Fig. 8, Table 2). In general, neurons that were labeled after injections into the preSMA were located in more rostral regions of GPi than neurons that were labeled after injections into the SMA. Mid regions of GPi contained neurons that project to either cortical area. However, neurons projecting to the pre-SMA were more dorsally lo- cated in this mid region than neurons projecting to the SMA (Fig. 8 , histograms).

\section{Relationship of pallidal outputs to calbindin immunoreactivity}

Previous studies have used gradients in immunoreactivity to Calbindin D-28K (CB-ir) to define "sensorimotor," associative, and "limbic" territories in the striatum and the external segment of the globus pallidus (Côté et al., 1991; Côté and Parent,1992; François et al., 1994, 2004; for review, see Parent et al., 1996). In the present study, we observed similar gradients of CB-ir in the inner and outer portions of GPi (Fig. 9). In both portions of GPi, CB-ir is densest rostrally and declines gradually as one moves caudally. The densest CB-ir is located in rostroventral regions of both the outer and inner portions of GPi.

In general, neurons labeled after virus injections into the SMA were located in more caudal regions of GPi where CB-ir is relatively weak (compare Figs. 7, 9, 10). In contrast, we found that the neurons labeled after virus injections into the pre-SMA were located in the rostral regions of GPi where CB-ir is intense (Figs. 8, $9,11,12)$. Thus, the two cortical areas receive input from topographically separate and antigenically distinct territories in GPi.

\section{Ratio of basal ganglia to cerebellar labeling}

Because virus injections into SMA and pre-SMA labeled neurons in both GPi and dentate, we could examine the ratio of basal ganglia and cerebellar projections to these cortical areas in each animal (Table 2). Although there was some variability in results among animals, in most cases, the SMA and the pre-SMA received more input from GPi than from dentate. Specifically, the ratio of GPi to dentate neurons labeled after injections into the SMA averaged 2.9:1 and could be as high as 6.6:1. The results from injections into the pre-SMA were somewhat less variable. The ratio of GPi to dentate neurons averaged 4.3:1 and could be as high as 6.9:1. Thus, although the SMA and the pre-SMA are the targets of projections from both GPi and dentate, the magnitude of the input from GPi to these cortical areas is approximately three to four times greater than that from the dentate.

\section{Discussion}

There are three main observations of the present study. First, we found that the SMA and the pre-SMA are the targets of outputs from both the basal ganglia and the cerebellum. Second, our results indicate that the SMA and pre-SMA each receives relatively more basal ganglia input than cerebellar input. Third, projections to the SMA and pre-SMA originate from spatially separate and neurochemically distinct regions within GPi and dentate. Before discussing the implications of these and other observations, we would like to address one technical concern.

In general, the results after virus injections into the SMA were more variable in terms of number of labeled neurons and their location than were the results after virus injections into the preSMA. The origin of this variability is unclear, but it does not appear to be correlated with experimental factors such as survival time, total volume of virus injected, or number of sites injected. More importantly, similar variations have been observed in other studies that used conventional tracers to define origin of thalamic projections to the SMA (Schell and Strick, 1984; Wiesendanger and Wiesendanger, 1985a; Darian-Smith et al., 1990; Rouiller et al., 1994, 1999; Shindo et al., 1995; Matelli and Luppino, 1996; Sakai et al., 1999, 2002). In particular, the ratio of neurons labeled in basal ganglia recipient nuclei of the thalamus (VLo, VApc, VLm, VLcr) to neurons labeled in cerebellar recipient nuclei (X, 
SMA (DA8L)
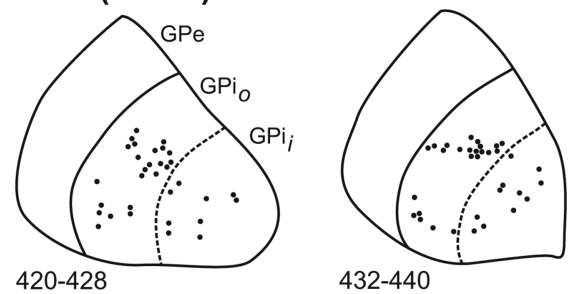

$432-440$
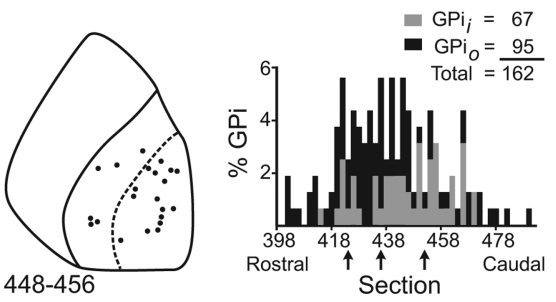

SMA (DA4L)

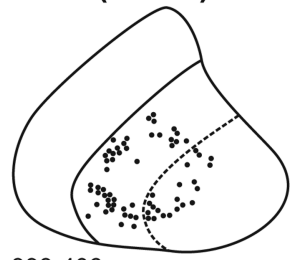

398-406

SMA (DA1L)
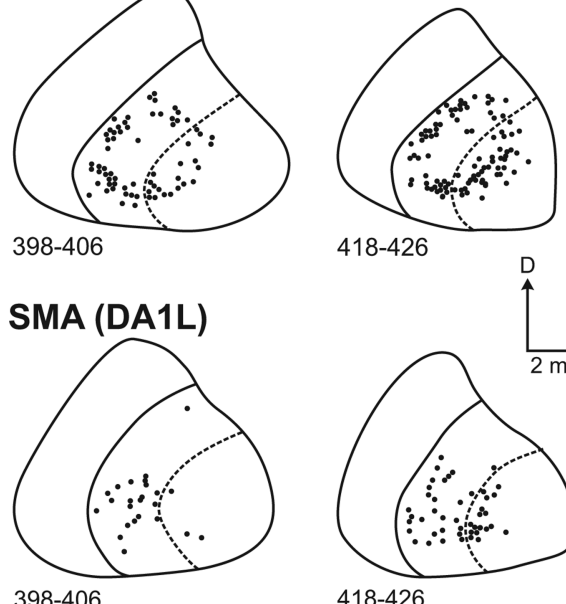

418-426
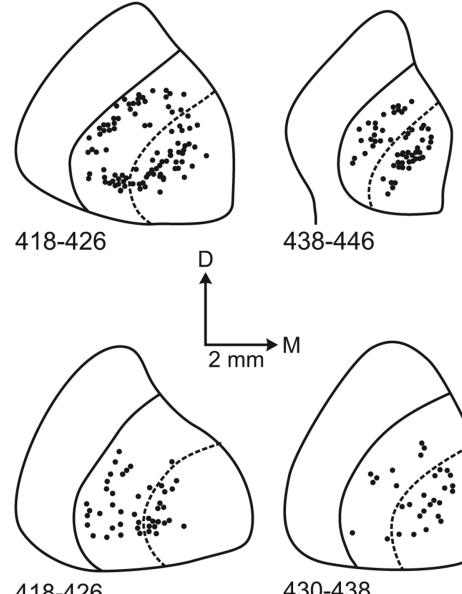

438-446
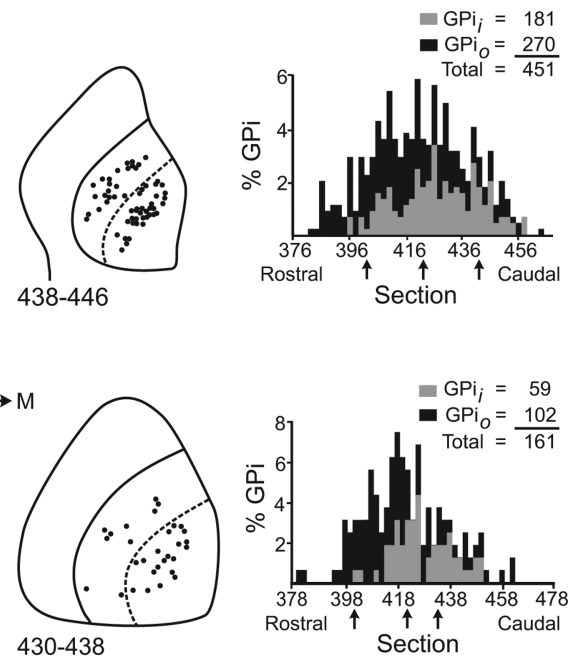

Figure 7. Second-order labeling in the GPi after virus injections into the SMA. Left, Coronal sections through the GPi nucleus from animals that received injections of virus into the SMA. Each black dot indicates the location of an infected neuron labeled by retrograde transneuronal transport (second-order neurons). Labeled cells from five sections spaced $100 \mu \mathrm{m}$ apart are superimposed on each outline of GPi. Section numbers are indicated below each plot. Right, Histograms of the rostrocaudal distribution of labeled neurons in the GPi for each case. Arrows indicate the location of the sections shown on the left. GPi ${ }_{i j}$ Inner portion of the $\mathrm{GPi} ; \mathrm{GPi}_{\boldsymbol{o}}$, outer portion of GPi; Total, total number of labeled neurons for each case.

\section{Pre SMA (DA7L)}

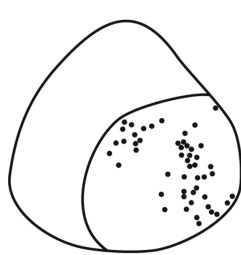

386-394

Pre SMA (DA8R)

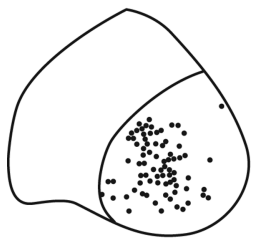

408-416
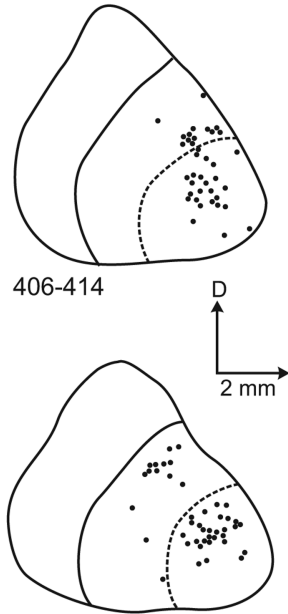

428-436

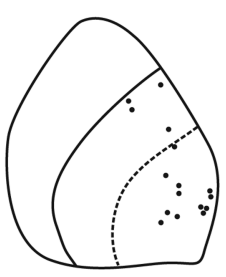

416-424

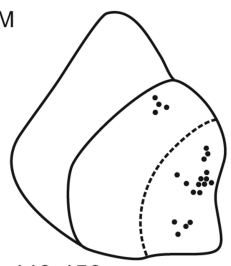

448-456

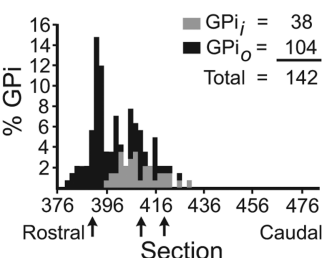

Section

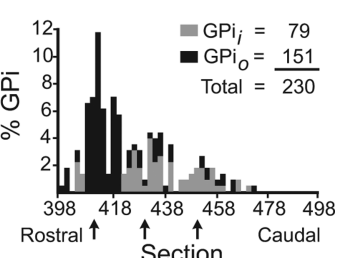

Section

SMA. We intend to explore this issue in the future by using anterograde transneuronal transport of the H129 strain of HSV1 from injection sites in the dentate and GPi (Kelly and Strick, 2003). This approach should enable us to determine whether basal ganglia and cerebellar systems terminate in separate zones (Holsapple et al., 1991) and/or in different cortical layers within the SMA (Nakano et al., 1992; McFarland and Haber, 2002). Whatever the origin of the variability in the results from SMA experiments, it has little overall impact on the main findings we discuss below.

The basal ganglia and cerebellum both project to the pre-SMA and SMA

There has been some uncertainly about the subcortical inputs to the pre-SMA and SMA (see Introduction for details and references). Once the pre-SMA and SMA were recognized as distinct, a number of anatomical studies provided evidence that the two cortical areas are the targets of outputs from the basal ganglia and cerebellum (Shindo et al., 1995; Inase et al., 1996; Matelli and Luppino, 1996; Rouiller et al., 1999; Sakai et al., 1999, 2000, 2002). Our results strongly support the conclusions of these previous studies. In addition, because transneuronal transport of virus occurs exclusively at synapses (Hoover and Strick., 1999; Kelly and Strick, 2000, 2003) [for references and review, see Card (2001)], our data provide evidence that cerebellar and pallidal efferents actually make synaptic connections with the thalamic neurons that project to each cortical area.

SMA and pre-SMA receive relatively more basal ganglia input than cerebellar input

Retrograde transneuronal transport of virus is unique in its ability to provide quantitative data on the relative number of subcortical neurons that are disynaptically connected with a cortical area (Hoover and Strick, 1999; Middleton and Strick, 2001a, 2002; Kelly and Strick, 2003) [for references and review, see Card (2001)]. In the present experiments, we determined the ratio of pallidal to cerebellar neurons that innervated an injection site (Table 2).

VPLo, VLcc) ranged from 0.9:1 to 6.4:1 $(n=8)$ (Shindo et al., 1995; Matelli and Luppino, 1996). This range is nearly identical to that of GPi/dentate neurons labeled in the present study after virus injections into the SMA (0.6:1-6.3:1) (Table 2). Thus, whatever the origin of the variability, it applies equally to studies using conventional and virus tracing methods.

At this point, we can only speculate on the origin of the variable patterns of transport observed after tracer injections into the
Overall, we found that the number of pallidal neurons that project to the pre-SMA and SMA is approximately three to four times greater than the number of cerebellar neurons that project to these cortical areas. Indeed, in three of our experiments, the ratio of basal ganglia to cerebellar input to these cortical areas was $>6: 1$ (Table 2).

Our results on subcortical inputs to the SMA are in accord with the findings of previous studies that used conventional trac- 
ers (Schell and Strick, 1984; Wiesendanger and Wiesendanger, 1985a; Rouiller et al., 1994; Shindo et al., 1995; Matelli et al., 1996; Sakai et al., 1999, 2002). In general, these studies found that (1) the most substantial input to the SMA originates from thalamic nuclei that are the target of basal ganglia efferents and (2) pallidal terminations are denser than cerebellar terminations in the thalamic nuclei that project to the SMA [for references and recent reviews, see Rouiller et al. (1994) and Sakai et al. $(1999,2002)]$.

Our results also are in accord with previous findings that the pre-SMA receives input both from the basal ganglia and the cerebellum (Inase et al., 1996; Matelli and Luppino, 1996; Sakai et al., 2000). However, there is some difference in opinion about the relative strength of basal ganglia and cerebellar input to the pre-SMA. Based on a quantitative analysis, Matelli and Luppino (1996) concluded that thalamic input to the preSMA comes equally from nuclei that are the target of basal ganglia and cerebellar input. In contrast, the plots of data shown by Inase et al. (1996) and Sakai et al. (2000) indicate that thalamic nuclei that are the target of basal ganglia efferents are the major source of input to the pre-SMA. Our results support these latter studies. Our injections of virus into the pre-SMA labeled from three to seven times as many pallidal neurons as cerebellar neurons. The differences in results among the various studies may be attributable to the size and extent of the injection sites in the pre-SMA. Our injection sites and those of Inase et al. (1996) and Sakai et al. (2000) were larger than those of Matelli and Luppino (1996) and thus involved more of the pre-SMA. Overall, we conclude that the pre-SMA receives both basal ganglia and cerebellar input, but, as a whole, the pre-SMA is dominated by basal ganglia input.

Comparison with other cortical areas We have previously used virus tracing to examine the organization of basal ganglia and cerebellar inputs to a number of motor, prefrontal, and posterior parietal areas of cortex (Dum and Strick, 1999; Hoover and Strick, 1999; Akkal et al., 2001; Clower et al., 2001, 2005; Middleton and Strick, 2001a, 2002). Some of these experiments used HSV1 as a tracer, and others used rabies (Table $3)$. The two viruses produced comparable ratios of labeled pallidal to dentate neurons when they were injected into the same cortical area of different animals. For example, HSV1 and rabies labeled comparable ratios of pallidal to dentate neurons after virus injections into $\mathrm{M} 1$ and into the ventral premotor area (PMv) (Table 3). Therefore, we have compared
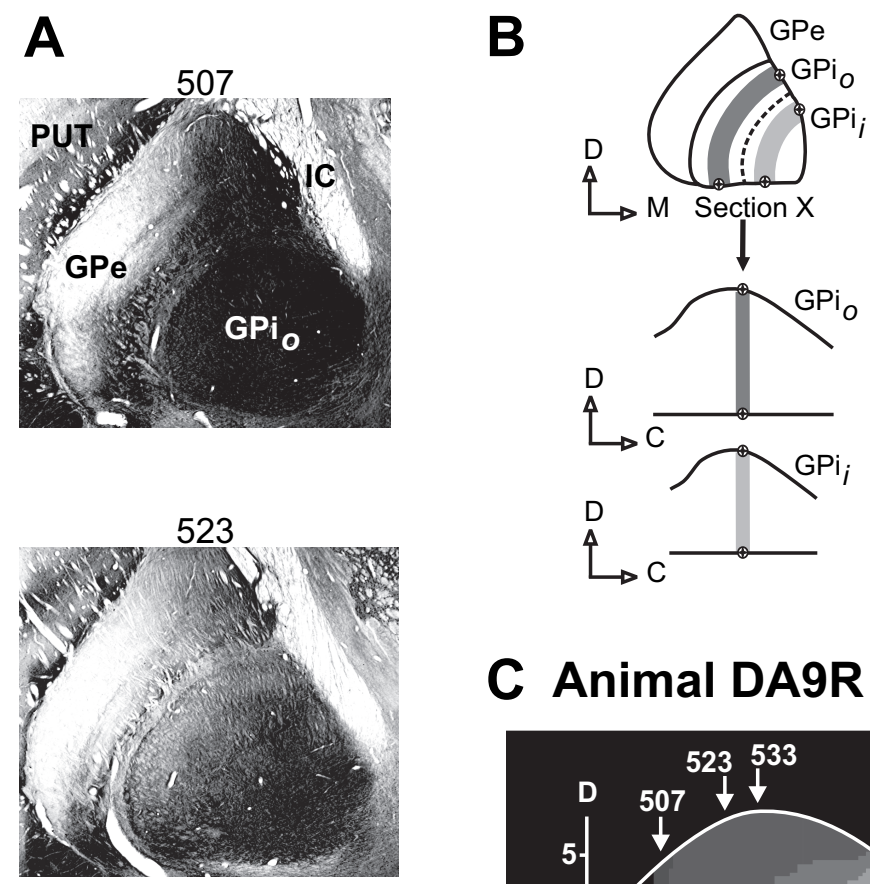

\section{Animal DA9R}

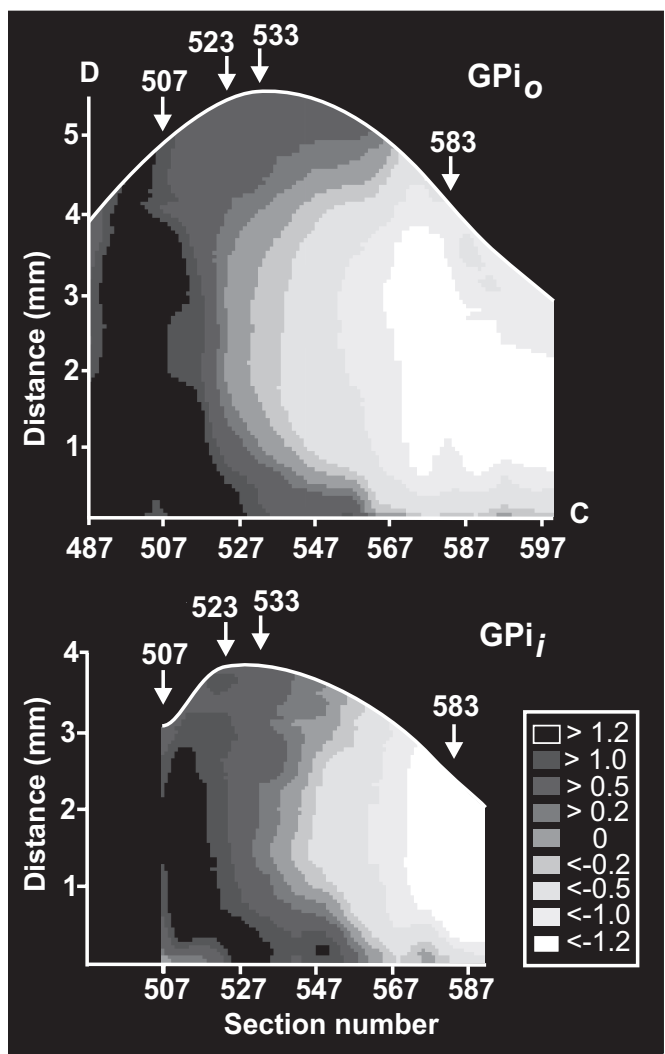

Figure 9. CB-ir in GPi. A, Photomicrographs of CB-immunoreactive staining in sections through the GPi. The section number is indicated above each photomicrograph. $\boldsymbol{B}$, Procedure for unfolding GPi. See Materials and Methods for details. C, Gradient density maps of CB-ir for the outer and inner portions of GPi. The intensity of $C B$-ir is contoured into nine levels from the most intense staining (darkest) to the least intense staining (lightest), relative to the mean (0 level). The units are in SDs from the mean. The black arrows indicate the rostrocaudal level of the sections shown in $\boldsymbol{A}$. IC, Internal capsule; PUT, putamen; GPi ${ }_{i}$, inner portion of the $\mathrm{GPi} ; \mathrm{GPi}_{0}$, outer portion of GPi; GPe, external segment of the globus pallidus; $D$, dorsal; M, medial; $C$, caudal.

the ratio of basal ganglia (i.e., GPi and SNpr) to cerebellar (dentate) neurons labeled after virus injections into a range of motor and nonmotor areas of the cerebral cortex (Table 3). This analysis shows that, on average, equal numbers of basal ganglia and cerebellar neurons innervate motor and posterior parietal areas of cortex. In contrast, the number of pallidal neurons that project to areas of prefrontal cortex is, in all cases, more than two to three times the number of dentate neurons that innervate the same areas. In fact, some prefrontal 


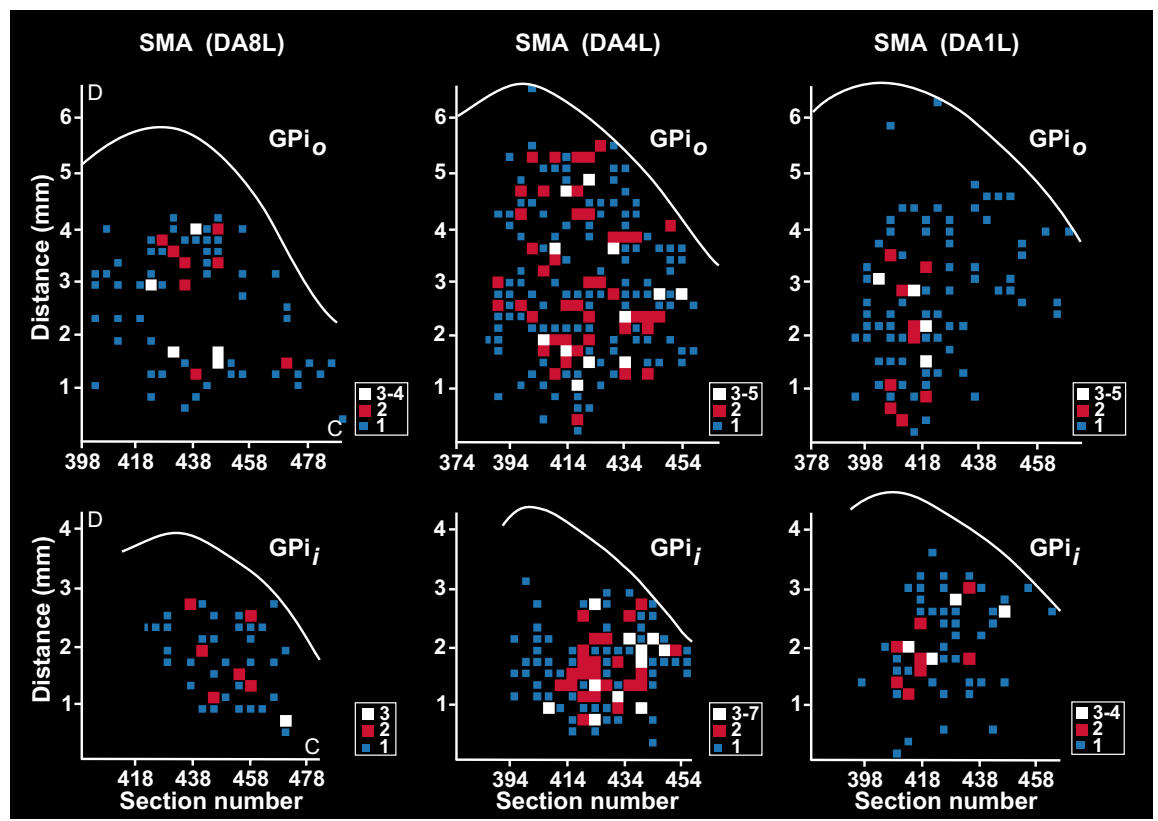

Figure 10. Unfolded maps of the pallidal neurons that project to the SMA. The panels show unfolded maps of the distribution and density of second-order neurons that were labeled by retrograde transneuronal transport of virus from the SMA. The top row indicates labeling in $\mathrm{GPi}_{\boldsymbol{o}}$, and the bottom row shows labeling in $\mathrm{GPi}_{i}$. The maps were generated from plots of every other coronal section through GPi. The colored squares are coded to indicate the number of labeled neurons in $200 \mu \mathrm{m}$ bins throughout the nucleus (the color code is given in the bottom right corner of each panel). See Materials and Methods for the procedures used to unfold and chart the density of labeled neurons in GPi.

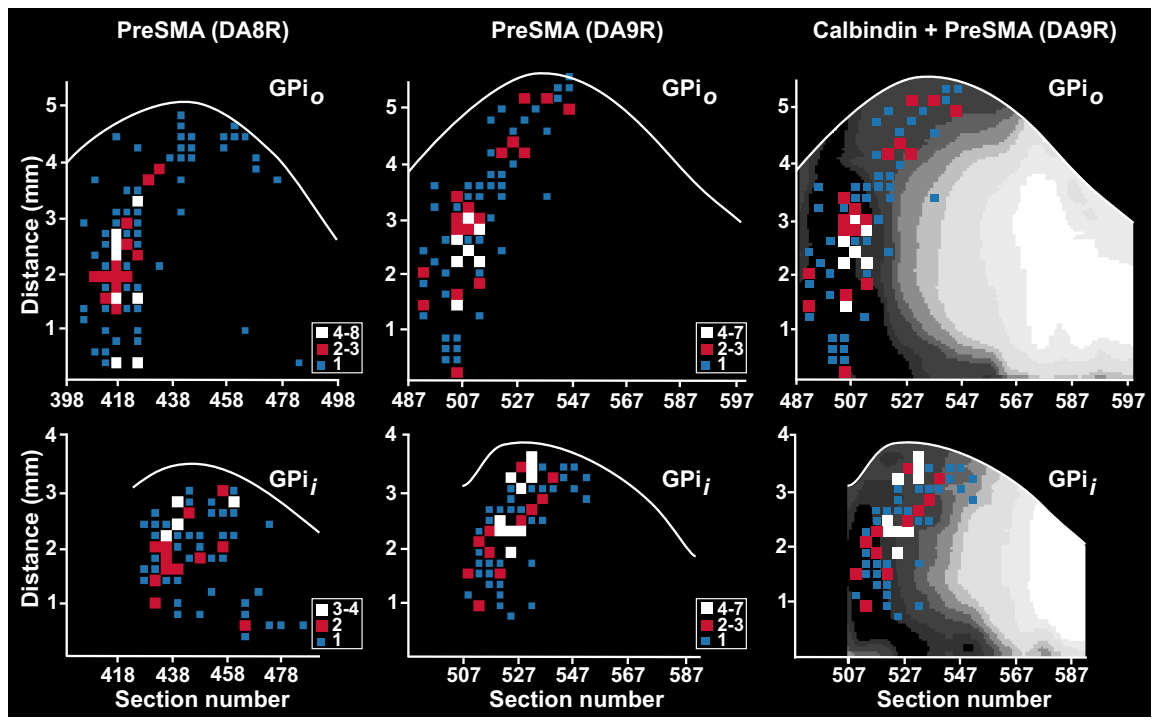

Figure 11. Unfolded maps of the pallidal neurons that project to the pre-SMA. The left and middle columns show unfolded maps of the distribution and density of second-order neurons that were labeled by retrograde transneuronal transport of virus from the pre-SMA. The top row indicates labeling in $\mathrm{GPi}_{o^{\prime}}$ and the bottom row shows labeling in $\mathrm{GPi}_{i}$. Conventions are as in Figure 10. The right column shows a gradient density map of CB-ir in GPi, overlaid with pallidal labeling after an injection into the pre-SMA (animal DA9R).

regions are dominated by basal ganglia input (e.g., area $9 \mathrm{~m}$, 16:1 ratio) or may receive no cerebellar input at all [e.g., area 12 (Middleton and Strick, 2002)]. In this respect, the SMA and especially the pre-SMA appear to be more like regions of prefrontal cortex than like regions of motor and posterior parietal cortex. This result further emphasizes the unique prominence of basal ganglia input to the SMA and pre-SMA.
Pre-SMA and SMA receive input from neurochemically distinct regions of the dentate and GPi

Transneuronal transport of virus also enabled us to determine the location of basal ganglia and cerebellar neurons that project (via the thalamus) to a cortical area. We found that the dentate neurons that project to the pre-SMA are located in a ventral region of the nucleus where staining for antibody $8 \mathrm{~B} 3$ is intense (Fig. 6). We have previously termed this region the nonmotor domain of the dentate, in part because it also contains neurons that project to regions of prefrontal cortex (e.g., areas 46 and 9) (Middleton and Strick, 2001a; Dum and Strick, 2003). In contrast, dentate neurons that project to the SMA are located in a more dorsal region of the nucleus where staining for antibody $8 \mathrm{~B} 3$ is weak. We have termed this region the motor domain of the dentate because it contains neurons that project to the primary motor cortex and premotor areas on the lateral surface of the hemisphere (Dum and Strick, 2003). Wiesendanger and Wiesendanger (1985b) reported a similar (although not identical) separation between the dentate neurons that innervate the pre-SMA (their "rostral" SMA) and the SMA proper. Thus, although the pre-SMA and SMA are located next to each other on the medial wall of the hemisphere, the dentate regions that project to the two cortical areas are located in spatially separate and neurochemically distinct regions of the nucleus.

The pre-SMA and SMA also are the target of distinct projections from GPi (Fig. 12). The pallidal neurons that project to the pre-SMA are located in a rostral region of the nucleus where $\mathrm{CB}$-ir is intense. Pallidal regions with dense CB-ir have been considered to be part of the associative territory of the basal ganglia (Côté et al., 1991; François et al., 1994, 2004; for review, see Parent et al., 1996). Results from our previous studies indicate that the associative territory of GPi includes regions that project to parts of prefrontal cortex such as areas 46 and 9 (Middleton and Strick, 2002). In contrast, pallidal neurons that project to the SMA are located in a more caudal and ventral region of the nucleus where $\mathrm{CB}$-ir is relatively weak. Pallidal regions with weak CB-ir have been considered to be part of the sensorimotor territory of the basal ganglia. Our previous results indicate that this territory of GPi contains neurons that project to $\mathrm{M} 1$ and the premotor areas on the lateral surface of the hemisphere (Hoover and Strick, 1993, 1999). Thus, the pre-SMA and SMA receive input from neurons located in spatially separate and neurochemically distinct regions of GPi. 


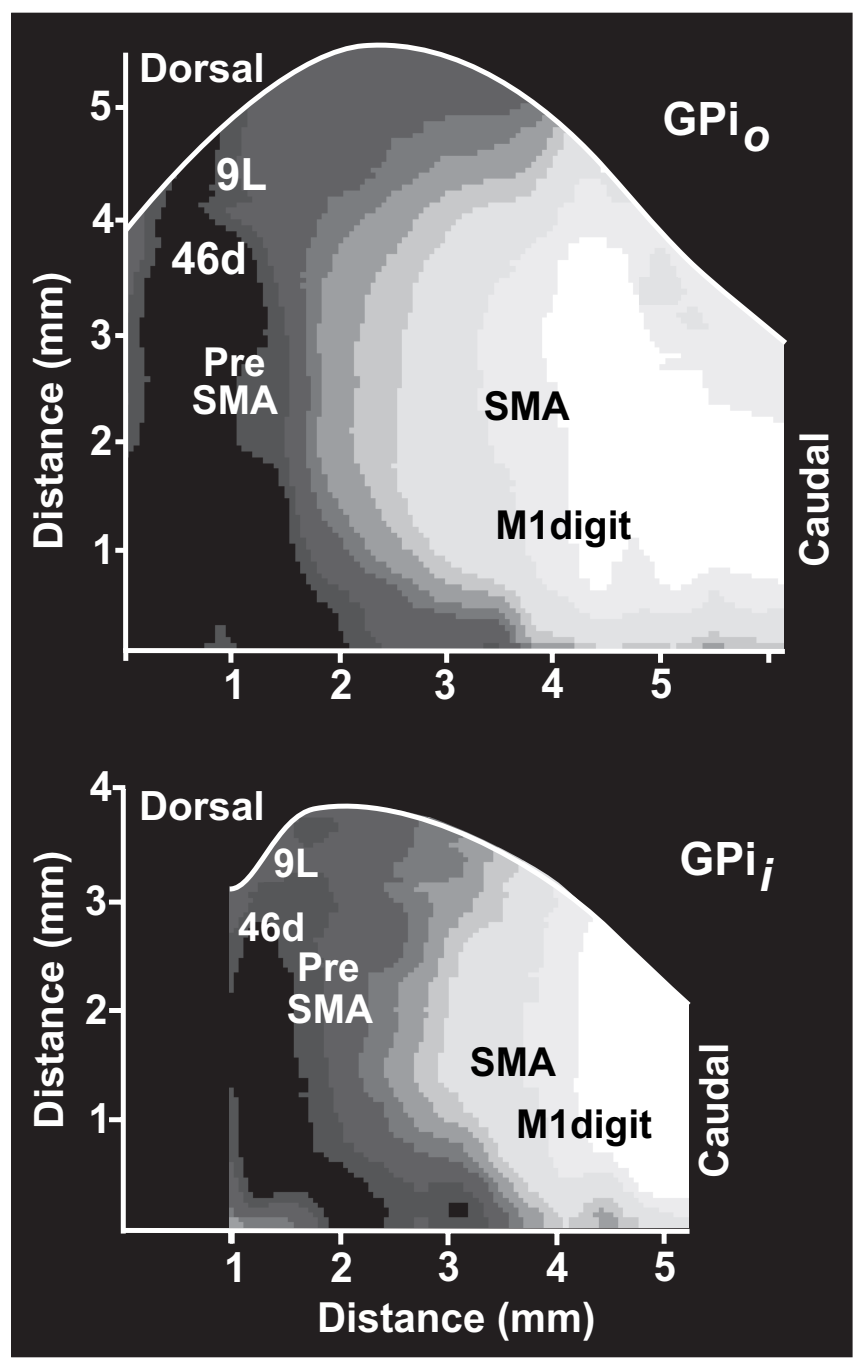

Figure 12. Summary map of the GPi output channels and their relationship to CB-ir. The location of known output channels in the dentate is overlaid on a map of CB-ir (from animal $D A 9 R)$. The cortical target of the output channel is placed at the site of the peak labeling after retrograde transneuronal transport of virus from that cortical area. $\mathrm{GPi}_{i}$, Inner portion of the GPi; $\mathrm{GPi}_{\boldsymbol{o}}$, outer portion of GPi.

\section{The pre-SMA is not a typical motor area}

Our data are fully consistent with the view that the SMA is one of the premotor areas in the frontal lobe. Like other premotor areas, the SMA (1) has dense projections to M1 (Muakkassa and Strick, 1979; Ghosh et al., 1987; Luppino et al., 1990, 1993; Dum and Strick, 1991b, 2005; Hatanaka et al., 2001; Wang et al. 2001), (2) has substantial projections directly to the spinal cord (Dum and Strick, 1991a, 1996, 2005; Galea and Darian-Smith, 1994; He et al., 1995; Maier et al., 2002), (3) receives basal ganglia and cerebellar input from the motor domains of GPi and dentate (present study), and (4) lacks dense interconnections with prefrontal cortex (Luppino et al., 1990, 1993; Bates and Goldman-Rakic, 1993; Morecraft and Van Hoesen, 1993; Lu et al., 1994).

In contrast, the pre-SMA is anatomically more like a region of prefrontal cortex because it (1) does not project directly to M1 (Dum and Strick, 1991b, 2005; Tokuno and Tanji, 1993; Lu et al., 1994; Hatanaka et al., 2001; Wang et al., 2001), (2) does not project to the spinal cord (Dum and Strick, 1991a, 2005; Galea and Darian-Smith, 1994; He et al., 1995), (3) receives basal ganglia and cerebellar input from the nonmotor domain of GPi and dentate (present study), and (4) is densely interconnected with several regions of prefrontal cortex (Luppino et al., 1990, 1993; Bates and Goldman-Rakic, 1993; Lu et al., 1994; Wang et al., 2005) (but see Takada et al., 2004).

A number of recent observations from neurophysiological and imaging studies emphasize the nonmotor nature of pre-SMA function. For example, during neuron recording studies in monkeys, Tanji and colleagues (Matsuzaka and Tanji, 1996; Shima et al., 1996; see also Akkal et al., 2002a) discovered neurons in the pre-SMA that discharge specifically when an animal shifted from one task plan to another. In subsequent studies, Shima and Tanji (2006) found neurons in the pre-SMA that were active for oddor even-numbered trials of a task. During imaging studies in humans, activation was present in the pre-SMA during tasks requiring attention to time (Coull et al., 2004; Pouthas et al., 2005; Macar et al., 2006), attention to changing visual stimuli (Hon et al., 2006), and "attention to intention" rather than "attention to movement" (Lau et al., 2004). Thus, the function of the pre-SMA appears to be related to some aspect of attention required during cognitively demanding tasks.

\section{Functional implications: cortico-subcortical loops}

In the original proposal on the organization of basal ganglia loops with the frontal lobe (Alexander et al., 1986), five different cortical areas were the target of separate basal ganglia circuits. A source of input and the target of output from the "motor circuit" was the SMA. We now know that (1) more than five parallel loops link motor and nonmotor areas in the frontal lobe with the basal ganglia and (2) basal ganglia output is directed to more than a single cortical motor area (Hoover and Strick, 1993, 1999; Middleton and Strick, 2001b). Inase et al. (1999) demonstrated that the SMA and pre-SMA project to essentially separate regions of the striatum, the input stage of basal ganglia processing. As a consequence, it is likely that the SMA and pre-SMA influence separate regions of the GPi. In the present study, we demonstrated that the SMA and pre-SMA receive input from separate regions within GPi. Together, these results suggest that the SMA and pre-SMA are each part of a distinct, closed-loop circuit with the basal ganglia.

\section{The relative strength of basal ganglia input to the SMA has clinical implications}

It is now well established that Parkinson's disease (PD) results from the degeneration of dopamine-producing cells in the pars compacta of the substantia nigra (SNpc). The specific set of SNpc cells that degenerate project to the sensorimotor territory of the striatum (Kish et al., 1988; Damier et al., 1999). The symptoms of PD appear when $>80 \%$ of dopamine is depleted from this striatal territory (Bernheimer et al., 1973). The output of the sensorimotor territory projects not only to the SMA but also to M1, the $\mathrm{PMv}$, and several other cortical motor areas in the frontal lobe (Hoover and Strick, 1993, 1999; Dum and Strick, 1999; Middleton and Strick, 2002; Kelly and Strick, 2004). Based on current models of PD pathophysiology (DeLong, 1990; Wichmann and DeLong, 2003), one would predict that this pattern of dopamine depletion would result in hypoactivation of all of the cortical areas influenced by the sensorimotor territory of the striatum. Yet, imaging studies of PD patients have found decreased activation in the SMA and increased activation in M1 and areas of premotor cortex (Playford et al., 1992; Rascol et al., 1992, 1994; Jahanshahi et al., 1995; Samuel et al., 1997, 2001; Sabatini et al., 2000; Haslinger et al., 2001; for review, see Grafton, 2004). Imaging studies of PD patients also observed increased activation in the cerebellum (Rascol et al., 1997; Samuel et al., 1997). The 
Table 3. Input from basal ganglia and cerebellum

\begin{tabular}{lllr}
\hline Experiment & Virus & Number & BG/CB ratio \\
\hline Area 9m & HSV1 & 2 & $16: 1$ \\
Area 9l & HSV1 & 2 & $3.9: 1$ \\
Area 46 & HSV1 & 3 & $2.7: 1$ \\
Pre-SMA & RV & 3 & $4.3: 1$ \\
SMA & HSV1/RV & 7 & $\mathbf{2 . 9 : 1}$ \\
PMv digit & RV & 2 & $1: 1$ \\
PMv arm & HSV1 & 3 & $1: 1$ \\
M1 digit & RV & 4 & $1.1: 1$ \\
M1 arm & HSV1 & 4 & $0.8: 1$ \\
Area AIP & RV & 3 & $1.1: 1$ \\
\hline
\end{tabular}

RV, Rabies virus; $\mathrm{BG}$, basal ganglia; $\mathrm{CB}$, cerebellum.

increased cerebellar activation may be part of an adaptive response to compensate for the cortical hypoactivity that would result from basal ganglia dysfunction in PD (Rascol et al., 1997; Samuel et al., 1997). If this is the case, why then would cerebellar hyperactivity not normalize activity in the SMA?

Our results may provide some explanation for these puzzling observations. We found that the SMA is unlike other cortical motor areas in having three to four times more basal ganglia input than cerebellar input. Thus, we speculate that the relative weakness of the cerebellar input to the SMA may not allow an increase in cerebellar output to normalize SMA activity in PD. If our speculation is correct, then it implies that treatments for $\mathrm{PD}$ might focus on attempts to normalize SMA function. However, one could adopt an alternative view that cerebellar hyperactivity and the attendant hyperactivity in M1 and the other cortical motor areas is part of the problem, rather than part of the solution (Grafton, 2004). Whichever perspective is correct, our results suggest that defining the ratio of basal ganglia and cerebellar inputs to specific cortical areas may provide some new insights into the pathophysiology of basal ganglia disorders.

\section{References}

Akkal D, Dum RP, Strick PL (2001) Cerebellar and pallidal inputs to the supplementary motor area (SMA). Soc Neurosci Abstr 27:825.4.

Akkal D, Bioulac B, Audin J, Burbaud P (2002a) Comparison of neuronal activity in the rostral supplementary and cingulate motor areas during a task with cognitive and motor demands. Eur J Neurosci 15:887-904.

Akkal D, Dum RP, Strick PL (2002b) Cerebellar and pallidal inputs to the pre-supplementary motor area (preSMA). Soc Neurosci Abstr 28:462.14.

Akkal D, Dum RP, Strick PL (2003) Calbindin D-28K immunoreactivity reflects the topographic organization of motor and non-motor outputs channels in the globus pallidus. Soc Neurosci Abstr 29:601.4.

Alexander GE, Crutcher MD (1990) Preparation for movement: neural representations of intended direction in three motor areas of the monkey. J Neurophysiol 64:133-150.

Alexander GE, DeLong MR, Strick PL (1986) Parallel organization of functionally segregated circuits linking basal ganglia and cortex. Annu Rev Neurosci 9:357-381.

Bates JF, Goldman-Rakic PS (1993) Prefrontal connections of medial motor areas in the rhesus monkey. J Comp Neurol 336:211-228.

Bernheimer H, Birkmayer W, Hornykiewicz O, Jellinger K, Seitelberger F (1973) Brain dopamine and the syndromes of Parkinson and Huntington. Clinical, morphological and neurochemical correlations. J Neurol Sci 20:415-455.

Brinkman C, Porter R (1979) Supplementary motor area in the monkey: activity of neurons during performance of a learned motor task. J Neurophysiol 42:681-709.

Card JP (2001) Pseudorabies virus neuroinvasiveness: a window into the functional organization of the brain. In: Advances in virus research, $\mathrm{Vol}$ 56, Neurovirology: viruses and the brain (Buchmeier MJ, Campbell IL, eds), pp 39-71. San Diego: Academic.

Clower DM, West RA, Lynch JC, Strick PL (2001) The inferior parietal lob- ule is the target of output from the superior colliculus, hippocampus, and cerebellum. J Neurosci 21:6283-6291.

Clower DM, Dum RP, Strick PL (2005) Basal ganglia and cerebellar inputs to "AIP." Cereb Cortex 15:913-920.

Côté PY, Parent A (1992) Calbindin D-28K and choline acetyltransferase are expressed by different neuronal populations in pedunculopontine nucleus but not in nucleus basalis in squirrel monkeys. Brain Res 593:245-252.

Côté PY, Sadikot AF, Parent A (1991) Complementary distribution of calbindin D-28K and parvalbumin in the basal forebrain and midbrain of the squirrel monkey. Eur J Neurosci 3:1316-1329.

Coull JT, Vidal F, Nazarian B, Macar F (2004) Functional anatomy of the attentional modulation of time estimation. Science 303:1506-1508.

Damier P, Hirsch EC, Agid Y, Graybiel AM (1999) The substantia nigra of the human brain. II. Patterns of loss of dopamine-containing neurons in Parkinson's disease. Brain 122:1437-1448.

Darian-Smith C, Darian-Smith I, Cheema SS (1990) Thalamic projections to sensorimotor cortex in the macaque monkey: use of multiple retrograde fluorescent tracers. J Comp Neurol 1990 299:17-46.

DeLong MR (1990) Primate models of movement disorders of basal ganglia origin. Trends Neurosci 13:281-285.

Dum RP, Strick PL (1991a) The origin of corticospinal projections from the premotor areas in the frontal lobe. J Neurosci 11:667-689.

Dum RP, Strick PL (1991b) Premotor areas: nodal points for parallel efferent systems involved in the central control of movement. In: Motor control: concepts and issues (Humphrey DR, Freund H-J, eds), pp 383-397. New York: Wiley.

Dum RP, Strick PL (1996) Spinal cord terminations of the medial wall motor areas in macaque monkeys. J Neurosci 16:6513-6525.

Dum RP, Strick PL (1999) Pallidal and cerebellar inputs to the digit representation of the lateral premotor areas. Soc Neurosci Abstr 25:1925.

Dum RP, Strick PL (2003) An unfolded map of the cerebellar dentate nucleus and its projections to the cerebral cortex. J Neurophysiol 89:634-639.

Dum RP, Strick PL (2005) Frontal lobe inputs to the digit representations of the motor areas on the lateral surface of the hemisphere. J Neurosci 25:1375-1386.

Dum RP, Li C, Strick PL (2002) Motor and nonmotor domains in the monkey dentate. Ann NY Acad Sci 978:289-301.

François C, Yelnik J, Percheron G, Tandé D (1994) Calbindin D-28k as a marker for the associative cortical territory of the striatum in macaque. Brain Res 633:331-336.

François C, Grabli D, McCairn K, Jan C, Karachi C, Hirsch EC, Féger J, Tremblay L (2004) Behavioral disorders induced by external globus pallidus dysfunction in primates II. Anatomical study. Brain 127:2055-2070.

Galea MP, Darian-Smith I (1994) Multiple corticospinal neuron populations in the macaque monkey are specified by their unique cortical origins, spinal terminations, and connections. Cereb Cortex 4:166-194.

Ghosh S, Brinkman C, Porter R (1987) A quantitative study of the distribution of neurons projecting to the precentral motor cortex in the monkey (M. fascicularis). J Comp Neurol 259:424-444.

Gillet JP, Derer P, Tsiang H (1986) Axonal transport of rabies virus in the central nervous system of the rat. J Neuropathol Exp Neurol 45:619-634.

Goldberg G (1985) Supplementary motor area structure and function: Rev and hypotheses. Behav Brain Sci 8:567-616.

Grafton ST (2004) Contributions of functional imaging to understanding parkinsonian symptoms. Curr Opin Neurobiol 14:715-719.

Haslinger B, Erhard P, Kampfe N, Boecker H, Rummeny E, Schwaiger M, Conrad B, Ceballos-Baumann AO (2001) Event-related functional magnetic resonance imaging in Parkinson's disease before and after levodopa. Brain 124:558-570.

Hatanaka N, Nambu A, Yamashita A, Takada M, Tokuno H (2001) Somatotopic arrangement and corticocortical inputs of the hindlimb region of the primary motor cortex in the macaque monkey. Neurosci Res 40:9-22. He SQ, Dum RP, Strick PL (1995) Topographic organization of corticospi- 
nal projections from the frontal lobe: motor areas on the medial surface of the hemisphere. J Neurosci 15:3284-3306.

Holsapple JW, Preston JB, Strick PL (1991) The origin of thalamic inputs to the "hand" representation in the primary motor cortex. J Neurosci 11:2644-2654.

Hon N, Epstein RA, Owen AM, Duncan J (2006) Frontoparietal activity with minimal decision and control. J Neurosci 26:9805-9809.

Hoover JE, Strick PL (1993) Multiple output channels in the basal ganglia. Science 259:819-821.

Hoover JE, Strick PL (1999) The organization of cerebellar and basal ganglia outputs to primary motor cortex as revealed by retrograde transneuronal transport of herpes simplex virus type 1. J Neurosci 19:1446-1463.

Inase M, Sakai ST, Tanji J (1996) Overlapping corticostriatal projections from the supplementary motor area and the primary motor cortex in the macaque monkey: an anterograde double labeling study. J Comp Neurol 373:283-296.

Inase M, Tokuno H, Nambu A, Akazawa T, Takada M (1999) Corticostriatal and corticosubthalamic input zones from the presupplementary motor area in the macaque monkey: comparison with the input zones from the supplementary motor area. Brain Res 833:191-201.

Jahanshahi M, Jenkins IH, Brown RG, Marsden CD, Passingham RE, Brooks DJ (1995) Self-initiated versus externally triggered movements. I. An investigation using measurement of regional cerebral blood flow with PET and movement-related potentials in normals and Parkinson's disease subjects. Brain 118:913-933.

Kaneda K, Nambu A, Tokuno H, Takada M (2002) Differential processing patterns of motor information via striatopallidal and striatonigral projections. J Neurophysiol 88:1420-1432.

Kelly RM, Strick PL (2000) Rabies as a transneuronal tracer of circuits in the central nervous system. J Neurosci Methods 103:63-71.

Kelly RM, Strick PL (2003) Cerebellar loops with motor cortex and prefrontal cortex of a nonhuman primate. J Neurosci 23:8432-8444.

Kelly RM, Strick PL (2004) Macro-architecture of basal ganglia loops with the cerebral cortex: use of rabies virus to reveal multisynaptic circuits. Prog Brain Res 143:449-459.

Kish SJ, Shannak K, Hornykiewicz O (1988) Uneven pattern of dopamine loss in the striatum of patients with idiopathic Parkinson's disease. Pathophysiologic and clinical implications. N Engl J Med 318:876-880.

Lau HC, Rogers RD, Haggard P, Passingham RE (2004) Attention to intention. Science 303:1208-1210.

Lu MT, Preston JB, Strick PL (1994) Interconnections between the prefrontal cortex and the premotor areas in the frontal lobe. J Comp Neurol 341:375-392.

Luppino G, Matelli M, Rizzolatti G (1990) Cortico-cortical connections of two electrophysiologically identified arm representations in the mesial agranular frontal cortex. Exp Brain Res 82:214-218.

Luppino G, Matelli M, Camarda RM, Gallese V, Rizzolatti G (1991) Multiple representations of body movements in mesial area 6 and the adjacent cingulate cortex: an intracortical microstimulation study in the macaque monkey. J Comp Neurol 311:463-482.

Luppino G, Matelli M, Camarda R, Rizzolatti G (1993) Corticocortical connections of area F3 (SMA-proper) and area F6 (pre-SMA) in the macaque monkey. J Comp Neurol 338:114-140.

Macar F, Coull J, Vital F (2006) The supplementary motor area in motor and perceptual time processing: fMRI studies. Cogn Process 7:89-94.

Macpherson JM, Marangoz C, Miles TS, Wiesendanger M (1982) Microstimulation of the supplementary motor area (SMA) in the awake monkey. Exp Brain Res 45:410-416.

Maier MA, Armand J, Kirkwood PA, Yang HW, Davis JN, Lemon RN (2002) Differences in the corticospinal projection from primary motor cortex and supplementary motor area to macaque upper limb motoneurons: an anatomical and electrophysiological study. Cereb Cortex 12:281-296.

Matelli M, Luppino G (1996) Thalamic input to mesial and superior area 6 in the macaque monkey. J Comp Neurol 372:59-87.

Matsuzaka Y, Tanji J (1996) Changing directions of forthcoming arm movements: neuronal activity in the presupplementary and supplementary motor area of monkey cerebral cortex. J Neurophysiol 76:2327-2342.

Matsuzaka Y, Aizawa H, Tanji J (1992) A motor area rostral to the supplementary motor area (presupplementary motor area) in the monkey: neuronal activity during a learned motor task. J Neurophysiol 68:653-662.

McFarland NR, Haber SN (2002) Thalamic relay nuclei of the basal ganglia form both reciprocal and nonreciprocal cortical connections, linking multiple frontal cortical areas. J Neurosci 22:8117-8132.

Middleton FA, Strick PL (2001a) Cerebellar projections to the prefrontal cortex of the primate. J Neurosci 21:700-712.

Middleton FA, Strick PL (2001b) A revised neuroanatomy of frontalsubcortical circuits. In: Frontal-subcortical circuits in psychiatry and neurological disorders (Lichter DG, Cummings JL, eds), pp 44-58. New York: Guilford.

Middleton FA, Strick PL (2002) Basal-ganglia "projections" to the prefrontal cortex of the primate. Cereb Cortex 12:926-935.

Mitz AR, Wise SP (1987) The somatotopic organization of the supplementary motor area: intracortical microstimulation mapping. J Neurosci 7:1010-1021.

Morecraft RJ, Van Hoesen GW (1993) Frontal granular cortex input to the cingulate (M3), supplementary (M2) and primary (M1) motor cortices in the rhesus monkey. J Comp Neurol 337:669-689.

Muakkassa KF, Strick PL (1979) Frontal lobe inputs to primate motor cortex: evidence for four somatotopically organized "premotor" areas. Brain Res 177:176-182.

Nakano K, Tokushige A, Kohno M, Hasegawa Y, Kayahara T, Sasaki K (1992) An autoradiographic study of cortical projections from motor thalamic nuclei in the macaque monkey. Neurosci Res 13:119-137.

Parent A, Fortin M, Côté PY, Cicchetti F (1996) Calcium-binding proteins in primate basal ganglia. Neurosci Res 25:309-334.

Penfield W, Welch K (1951) The supplementary motor area of the cerebral cortex; a clinical and experimental study. AMA Arch Neurol Psychiatry 66:289-317.

Petit L, Courtney SM, Ungerleider LG, Haxby JV (1998) Sustained activity in the medial wall during working memory delays. J Neurosci 18:9429-9437.

Petrides M, Pandya DN (1999) Dorsolateral prefrontal cortex: comparative cytoarchitectonic analysis in the human and the macaque brain and corticocortical connection patterns. Eur J Neurosci 11:1011-1036.

Picard N, Strick PL (1996) Motor areas of the medial wall: a review of their location and functional activation. Cereb Cortex 6:342-353.

Picard N, Strick PL (2001) Imaging the premotor areas. Curr Opin Neurobiol 11:663-672.

Pimenta AF, Strick PL, Levitt P (2001) Novel proteoglycan epitope expressed in functionally discrete patterns in primate cortical and subcortical regions. J Comp Neurol 430:369-388.

Playford ED, Jenkins IH, Passingham ER, Nutt J, Frackowiak RSJ, Brooks DJ (1992) Impaired mesial frontal and putamen activation in Parkinson's disease: a positron emission tomography study. Ann Neurol 32:151-161.

Pouthas V, George N, Poline JB, Pfeuty M, Vandemoorteele PF, Hugueville L, Ferrandez AM, Lehericy S, Lebihan D, Renault B (2005) Neural network involved in time perception: an fMRI study comparing long and short interval estimation. Hum Brain Mapp 25:433-441.

Rascol O, Sabatini U, Chollet F, Celsis P, Montastruc JL, Marc-Vergnes JP, Rascol (1992) A (1992) Supplementary and primary sensory motor area activity in Parkinson's disease. Regional cerebral blood flow changes during finger movements and effects of apomorphine. Arch Neurol 49:144-148.

Rascol O, Sabatini U, Chollet F, Fabre N, Senard JM, Montastruc JL, Celsis P, Marc-Vergnes JP, Rascol A (1994) Normal activation of the supplementary motor area in patients with Parkinson's disease undergoing longterm treatment with levodopa. J Neurol Neurosurg Psychiatry 57:567-571.

Rascol O, Sabatini U, Fabre N, Brefel C, Loubinoux I, Celsis P, Senard JM, Montastruc JL, Chollet F (1997) The ipsilateral cerebellar hemisphere is overactive during hand movements in akinetic parkinsonian patients. Brain 120:103-110.

Rosene DL, Mesulam MM (1978) Fixation variables in horseradish peroxidase neurohistochemistry. I. The effect of fixation time and perfusion procedures upon enzyme activity. J Histochem Cytochem 26:28-39.

Rouiller EM, Liang F, Babalian A, Moret V, Wiesendanger M (1994) Cerebellothalamocortical and pallidothalamocortical projections to the primary and supplementary motor cortical areas: a multiple tracing study in macaque monkeys. J Comp Neurol 345:185-213.

Rouiller EM, Tanne J, Moret V, Boussaoud D (1999) Origin of thalamic inputs to the primary, premotor, and supplementary motor cortical areas and to area 46 in macaque monkeys: a multiple retrograde tracing study. J Comp Neurol 409:131-152. 
Sabatini U, Boulanouar K, Fabre N, Martin F, Carel C, Colonnese C, Bozzao L, Berry I, Montastruc JL, Chollet F, Rascol O (2000) Cortical motor reorganization in akinetic patients with Parkinson's disease: a functional MRI study. Brain 123:394-403.

Sakai ST, Inase M, Tanji J (1999) Pallidal and cerebellar inputs to thalamocortical neurons projecting to the supplementary motor area in $\mathrm{Macaca}$ fuscata: a triple-labeling light microscopic study. Anat Embryol (Berl) 199:9-19.

Sakai ST, Stepniewska I, Qi HX, Kaas JH (2000) Pallidal and cerebellar afferents to pre-supplementary motor area thalamocortical neurons in the owl monkey: a multiple labeling study. J Comp Neurol 417:164-180.

Sakai ST, Inase M, Tanji J (2002) The relationship between MI and SMA afferents and cerebellar and pallidal efferents in the macaque monkey. Somatosens Mot Res 19:139-148.

Samuel M, Ceballos-Baumann AO, Blin J, Uema T, Boecker H, Passingham RE, Brooks DJ (1997) Evidence for lateral premotor and parietal overactivity in Parkinson's disease during sequential and bimanual movements. A PET study. Brain 120:963-976.

Samuel M, Ceballos-Baumann AO, Boecker H, Brooks DJ et al (2001) Motor imagery in normal subjects and Parkinson's disease patients: an H2150 PET study. NeuroReport 12:821-838.

Schell GR, Strick PL (1984) The origin of thalamic inputs to the arcuate premotor and supplementary motor areas. J Neurosci 4:539-560.

Schlag J, Schlag-Rey M (1987) Evidence for a supplementary eye field. J Neurophysiol 57:179-200.

Shima K, Tanji J (2006) Binary-coded monitoring of a behavioral sequence by cells in the pre-supplementary motor area. J Neurosci 26:2579-2582.

Shima K, Mushiake H, Saito N, Tanji J (1996) Role for cells in the presupplementary motor area in updating motor plans. Proc Natl Acad Sci USA 93:8694-8698.

Shindo K, Shima K, Tanji J (1995) Spatial distribution of thalamic projections to the supplementary motor area and the primary motor cortex: a retrograde multiple labeling study in the macaque monkey. J Comp Neurol 357:98-116

Strick PL, Card JP (1992) Transneuronal mapping of neural circuits with alpha herpesviruses. In: Experimental neuroanatomy: a practical approach (Bolam JP, ed), pp 81-101. Oxford: Oxford UP.

Suzuki S, Azuma M (1976) A glass-insulated "Elgiloy" microelectrode for recording unit activity in chronic monkey experiments. Electroencephalogr Clin Neurophysiol 41:93-95.

Takada M, Tokuno H, Nambu A, Inase M (1998a) Corticostriatal input zones from the supplementary motor area overlap those from the contrarather than ipsilateral primary motor cortex. Brain Res 791:335-340.

Takada M, Tokuno H, Nambu A, Inase M (1998b) Corticostriatal projections from the somatic motor areas of the frontal cortex in the macaque monkey: segregation versus overlap of input zones from the primary motor cortex, the supplementary motor area, and the premotor cortex. Exp Brain Res 120:114-128.

Takada M, Nambu A, Hatanaka N, Tachibana Y, Miyachi S, Taira M, Inase M (2004) Organization of prefrontal outflow toward frontal motor-related areas in macaque monkeys. Eur J Neurosci 19:3328-3342.

Tanji J (1994) The supplementary motor area in the cerebral cortex. Neurosci Res 19:251-268.

Tanji J (1996) New concepts of the supplementary motor area. Curr Opin Neurobiol 6:782-787.

Tokuno H, Tanji J (1993) Input organization of distal and proximal forelimb areas in the monkey primary motor cortex: a retrograde double labeling study. J Comp Neurol 333:199-209.

Walker AE (1940) A cytoarchitectural study of the prefrontal area of the macaque monkey. J Comp Neurol 73:59-86.

Wang Y, Shima K, Sawamura H, Tanji J (2001) Spatial distribution of cingulate cells projecting to the primary, supplementary, and presupplementary motor areas: a retrograde multiple labeling study in the macaque monkey. Neurosci Res 39:39-49.

Wang Y, Isoda M, Matsuzaka Y, Shima K, Tanji J (2005) Prefrontal cortical cells projecting to the supplementary eye field and presupplementary motor area in the monkey. Neurosci Res [Erratum (2005) 53:349] 53:1-7.

Wichmann T, DeLong MR (2003) Pathophysiology of Parkinson's disease: the MPTP primate model of the movement disorder. Ann NY Acad Sci 991:190-213.

Wiesendanger R, Wiesendanger M (1985a) The thalamic connections with medial area 6 (supplementary motor cortex) in the monkey (Macaca fascicularis). Exp Brain Res 59:91-104.

Wiesendanger R, Wiesendanger M (1985b) Cerebello-cortical linkage in the monkey as revealed by transcellular labeling with the lectin wheat germ agglutinin conjugated to the marker horseradish peroxidase. Exp Brain Res 59:105-117.

Woolsey CN, Settlage PH, Meyer DR, Sencer W, Hamuy TP, Travis AM (1952) Patterns of localization in precentral and "supplementary" motor area and their relation to the concept of a premotor area. Res Publ Assoc Res Nerv Ment Dis 30:238-264. 